NBER WORKING PAPER SERIES

\title{
INSURANCE OR SELF-INSURANCE?: \\ VARIATION, PERSISTENCE, AND \\ INDIVIDUAL HEALTH ACCOUNTS
}

\author{
Matthew J. Eichner \\ Mark B. McClellan \\ David A. Wise
}

Working Paper 5640

\section{NATIONAL BUREAU OF ECONOMIC RESEARCH 1050 Massachusetts Avenue \\ Cambridge, MA 02138 \\ June 1996}

Research support from the National Institutes of Health is gratefully acknowledged. We are also grateful to Jonathan Gruber for his comments. This paper is part of NBER's research programs in Health Care and Public Economics. Any opinions expressed are those of the authors and not those of the National Bureau of Economic Research.

(C) 1996 by Matthew J. Eichner, Mark B. McClellan and David A. Wise. All rights reserved. Short sections of text, not to exceed two paragraphs, may be quoted without explicit permission provided that full credit, including $\mathbb{C}$ notice, is given to the source. 


\title{
INSURANCE OR SELF-INSURANCE?: VARIATION, PERSISTENCE, AND INDIVIDUAL HEALTH ACCOUNTS
}

\begin{abstract}
We explore the feasibility of catastrophic health insurance established in conjunction with individual health accounts (IHAs). Under this plan, the employer establishes both a high-deductible health insurance plan and an IHA. Employee health care costs below the deductible are then paid out of the IHA; costs above the deductible are paid by the insurance plan. Assets remaining in the account when the employee retires are available for other purposes.

Although attractive because it helps to solve the "moral hazard" problem associated with conventional insurance plans, the scheme may be considered infeasible if medical expenditures over a working life are so persistent that certain individuals accumulate little in the IHA while others accumulate a great deal. Within the context of an illustrative IHA plan, we develop preliminary empirical evidence on the distribution of medical expenditures - and hence savings-under an IHA plan. Our analysis is based on longitudinal health insurance claims data from a large firm. We emphasize the balance in the IHA account at retirement. Although such a plan would produce a range of balances across employees, approximately $80 \%$ would retain over $50 \%$ of their contributions. Only about $5 \%$ would retain less than $20 \%$ of their contributions.

The outcomes suggest to us that such a plan is feasible. And, we believe that such a plan could be structured to increase retirement savings.
\end{abstract}

Matthew J. Eichner

Department of Economics

Massachusetts Institute of Technology

Cambridge, MA 02139

David A. Wise

Kennedy School of Government

Harvard University

79 JFK Street

Cambridge, MA 02138

and NBER
Mark B. McClellan

Department of Economics

Stanford University

Stanford, CA 94305-6072

and NBER 
Economists have for some time emphasized the desirable incentive properties of catastrophic health insurance. Under such a system individuals would pay for their own health care unless the expenses were very large. Thus the temptation to spend too much, the "moral hazard," that is created by typical insurance provisions, would be reduced or eliminated. Indeed, Arrow [1963] demonstrated that in the presence of moral hazard and risk aversion a catastrophic plan is optimal. A practical argument against catastrophic insurance, however, is that a very large fraction of families have almost no liquid savings and would find it hard to make even small out-of-pocket payments, especially if they were not anticipated. Perhaps in recognition of this fact, employees have shown a willingness to pay very high premia to avoid uncertainty about health expenditures and many firms have experienced very low participation rates in "major medical" plans with substantial deductibles even though these plans are typically offered at generously low premiums.

The attention of American health reformers in recent years has turned to managed care plans which place little reliance on "demand" incentives, instead using "supply-side" and contractual restrictions to limit spending under insurance plans with low deductibles and copayments. Apparently such plans have had some success in limiting health expenditures, although at the cost 
of increased regulation of doctor-patient transactions. But, ex-post, insured patients bear only a small fraction of cost of their care, suggesting incentives for cost control are far from optimal. We begin with this paper a research agenda that emphasizes -- and maybe reconsiders -- price incentives in health insurance reform.

We explore the feasibility of catastrophic health insurance established in conjunction with individual health accounts (IHAs). Such an arrangement holds the potential for both reducing health care cost and encouraging saving. Under this plan, the employer establishes both a high-deductible health insurance plan and an IHA. Annual contributions to the IHA are equal to a substantial fraction of the deductible. Employee health care costs below the deductible are then paid out of the IHA; costs above the deductible are paid by the insurance plan. Assets remaining in the account when the employee retires, or becomes Medicare-eligible, are then available for other purposes. The motivation for the parallel saving and insurance plans, of course, is that each employee is spending his or her "own" money for medical care, except in the event of serious illness. The plan thus combines the desirable features of catastrophic coverage for reducing medical expenditures, as advocated by Feldstein [1971] and by Feldstein and Gruber [1994], with a mechanism that creates a reserve from which individual expenses can be paid. 
But even if the IHA component provides the necessary liquidity, it may still be thought to be inequitable. To the extent that individuals experience different health shocks over many years, the plan could lead to large differences in IHA accumulations. A person who is never sick will accumulate large IHA balances, while someone who is always sick will accumulate nothing. If individual health expenditures over a working lifetime vary little, all persons will have the same IHA balance at retirement. On the other hand, if average individual expenditures vary widely over the working life, the plan may look like a savings plan to the healthy and self-insurance to the chronically ill. Though mitigating measures could be appended to a basic IHA plan to limit such inequality, unequal accumulation is an unavoidable consequence of individual financial risk. Equal accumulations under an IHA plan can only be guaranteed if all individuals have the same health shock experience over their lifetimes. Of course, equal premiums under a comprehensive health plan with first-dollar coverage also assure equal individual cost.

Because individual health shocks clearly vary, the feasibility of an IHA plan depends on whether the gains -- improved incentives for efficient healthcare spending and increased savings -- outweigh the costs -- more variation in individual health care costs than under more generous insurance plans. Indeed, we believe that in practice feasibility may depend largely on what the 
variation in IHA balances would "look like." Thus, as a crucial first step, we address that issue in this paper. Within the context of an illustrative IHA plan, we develop preliminary empirical evidence on the distribution of medical expenditures -- and hence savings -- under an IHA plan. Our analysis is based on longitudinal health insurance claims data from a large firm. In this analysis, we assume no behavioral response whatever to the increased cost sharing under an IHA plan. Feldstein and Gruber [1994] suggest that the response could be substantial. To the extent that individuals respond to price incentives, expenditure will be more equal -- perhaps substantially more equal -- than our results suggest. We hope to provide an upper bound on expenditure variation, as measured by variation in IHA accumulation.

We begin with examples that illustrate the enormous variation in health care costs in a single year and the persistence of individual expenditures from one year to the next. The illustrations are similar to those in McClellan and Wise [1994]. That paper emphasized persistence in individual health care costs and demonstrated that persons with large expenditures in one year are likely to have large average expenditures, whether calculated over one or several years. In addition, we emphasize here that, although not insignificant, the relationship between expenditures two years apart is substantially lower than the relationship between expenditures one year apart. And thus while 
persistence is important, the descriptive data also suggest that high expenditures levels typically do not last for many years.

Next we explain the statistical model that underlies our conclusions on the distribution of health care expenditures. The goal is to approximate the distribution of medical expenditures over a working lifetime in a large firm. We have data on employee expenditures over a three-year period. We estimate a model that captures the pattern of expenditures among employees and then use the model to simulate the lifetime distribution of expenditures. We give particular attention to two issues: One is the extent of persistence, the expected expenditure in one year conditional on expenditure in prior years. The second is the "unexplained" residual variance, or "shock" in expenditures, conditional on expenditure in prior years. An important aspect of the data is that this unexplained variance is very large and is not approximated well by any analytic distribution. Thus our simulation procedure depends heavily on non-parametric analysis based on the empirical distribution of conditional expenditures.

We next explain the results of simulations based on the model. We find that many employees will have no large medical expenditures over an entire working life. Others will have one or more episodes that generate large expenditures in one year and possibly in at least a few subsequent years as 
well. The concentration of expenditures that is observed in one year, and even when three years are combined, declines consistently as expenditures are cumulated over more years. Nonetheless, even of over a working lifetime there is a noticeable concentration of expenditures. We illustrate the implications of the concentration by considering the distribution of balances at retirement in an IHA account with a $\$ 2,000$ annual contribution. Although the vast majority of participants retire with substantial IHA balances, some incur substantial out-of-pocket costs and thus retire with only small balances. About $80 \%$ of employees are left with at least $50 \%$ of total IHA contributions, but about $5 \%$ have less than $20 \%$.

We conclude with a discussion of the implications and limitations of this preliminary analysis. We comment on issues that are not addressed and on future research plans.

\section{THE DATA AND SUMMARY DESCRIPTION.}

\section{A. Medical Claims Data.}

The data are medical claims of employees in a large Fortune 500 manufacturing firm. The analysis is based on all fee-for-service insurance claims over the three-year period 1989 through 1991. Over this period there 
were approximately 300,000 employees and their dependents covered through these insurance plans.

The firm has two fee-for-service plans, one for hourly and another for salaried employees. The hourly plan, with benefits negotiated in union contracts, provides "first-dollar" coverage for virtually all health care. Because of this virtually unlimited coverage, hourly employees have no financial incentives to join managed-care or HMO plans, though specific provider relationships and location considerations may provide some nonfinancial incentives. The salaried plan has an annual deductible of $\$ 200$ per individual and $\$ 250$ per family, a $20 \%$ coinsurance rate for all expenses, and an out-ofpocket annual limit (including the deductible) of $\$ 500$ per family. Routine physical examinations are not covered. Both plans incorporate limited case management for certain high-cost medical conditions and concurrent review of hospital stays. The hourly plan includes preadmission certification requirements for certain elective admissions; patients who elect admission despite precertification denial are responsible for $20 \%$ copayments up to $\$ 750$ per individual and $\$ 1500$ per family. Both plans also require second opinions for 16 elective surgical procedures, though the procedures are covered regardless of the second opinion finding. Both plans have very generous hospital stay limits: 365 days per stay, renewable after 60 days out of the 
hospital. Mental-health and substance-abuse inpatient care has a stricter day limit of 45 days, also renewable after 60 days out of the hospital. (During the time period of the study, a managed-care program was implemented for mental health and substance-abuse services.)

\section{B. Summary Data.}

Many studies have documented that medical expenditures in a particular year are concentrated among a small proportion of the insured. Less evidence, and hence less attention, has been directed to the persistence of individual expenditures over longer time periods and to the relationship between persistence and the concentration of expenditures. Together, both have important implications for insurance in general and in particular for the feasibility, incidence, and other consequences of insurance market reforms. Before presenting more formal analysis, we present descriptive evidence on these issues using longitudinal individual claims data for the period 1989 to 1991. We consider first a tabular description of the relationship between expenditures in three successive years. We then consider the concentration of expenditures and present more detailed descriptions of persistence, considering expenditures in consecutive years conditional on the decile (or quintile) ranking of expenditures in the first year. 
1. Medical Claims in Successive Years: The distributions of expenditures in 1990 and in 1991 conditional on 1989 expenditures are shown in Table 1. Consider, for example, persons 18 to 35 in the first panel of the table. Conditional on no expenditure in $1989,4 \%$ of persons have expenditures above $\$ 5000$ in 1990 . In contrast, over $20 \%$ of persons with expenditures above $\$ 5000$ in 1989 have expenditure above $\$ 5000$ in 1990 . Persistence appears to increase with age. Almost $30 \%$ of persons $46-55$ who had expenditures greater than $\$ 5000$ in 1989 also had expenditure greater than $\$ 5000$ in 1990 . In contrast, only $5 \%$ of the persons in this age group with no expenditure in 1989 had expenditures above $\$ 5000$ in 1990 . If there were no persistence across years, only $8 \%$ of the individuals with expenditures greater than $\$ 5000$ would have such high expenditures again in 1990.

Comparison of the first and second -- that shows data for 1991 conditional on spending in 1989 - panels of Table 1 reveals that persistence diminishes with time. For example, in the $18-35$ age group, about $15 \%$ of those with expenditure above $\$ 5,000$ in 1989 had expenditures above $\$ 5,000$ in 1991 , compared to almost $21 \%$ in 1990 . For the persons aged $46-55$, about $22 \%$ of those with expenditures above $\$ 5,000$ in 1989 had expenditures exceeding $\$ 5000$ in 1991, compared to almost $29 \%$ in 1990 . 
2. Individual Concentration of Expenditures: The relationship between persistence and concentration is shown in Figure 1. The Figure shows that in 1989 about $80 \%$ of cost was incurred by 10 percent of enrollees, roughly comparable to concentration results from other studies. Fifty percent of employees incurred virtually no cost. Figure 1 also shows the concentration of annual expenditures averaged over the two-year period of 1989 to 1990 , and over the three-year period of 1989 to 1991 . If there were no persistence in cost from one year to the next, costs averaged over several years would be much less concentrated among a few enrollees than costs in a single year. The curves show that although concentration declines as the time period increases, even over three years a small proportion of employees incur an enormous fraction of health care costs. Averaged over three years, $10 \%$ of enrollees account for a full $65 \%$ of expenditures. If there were no persistence from year to year, then averaged over many years the cost accounted for by the highest-cost decile would approach $10 \%$. The more formal analysis presented below shows that concentration declines continuously as more and more years of expenditures are cumulated, but is still substantial even averaged over a working lifetime.

3. Expenditure Decile and Subsequent Expenditures. Table 1 shows persistence in expenditures for selected age groups. Figure 2 presents 
a more detailed picture of persistence for all ages combined. Enrollees are divided into deciles based on 1989 claims. The figure shows expenditures in 1989 by decile, and then, also by 1989 decile, average annual expenditures one year later in 1990 and two years later in 1991. For comparison, the figure also shows average expenditures for all enrollees over these three years, which was $\$ 1,314$. Persons in the tenth decile in 1989 , in that year spent over eight times as much as the average. They spent close to five times the average in 1990 and almost three times the average in 1991. Averaged over all three years, those in the highest decile in 1989 spent about five times the average.

An alternative description is shown in Figures $3 a, 3 b$, and $3 c$. Figure $3 a$ shows the distribution of costs by quintile over the 1989 to 1991 period for each 1989 quintile (determined by 1989 expenditures). The figure shows, for example, that almost $60 \%$ of persons who were in the highest quintile in 1989 were also in the highest quintile averaged over three years. Another $35 \%$ were in the second highest quintile averaged over three years. By contrast fewer than $10 \%$ of persons in the lowest 1989 quintile were in the highest quintile over three years, and only about $10 \%$ were in the second highest quintile. Figure $3 b$ shows the distribution of costs in 1990 and Figure 3c shows the distribution in 1991, conditional on the 1989 quintile. Over $40 \%$ of 
persons in the highest quintile in 1989 are in the highest quintile in 1990 and about 35\% are in the highest quintile in 1991.

These descriptive data show that, on average, persons with high expenses in one year also tend to have much higher than average expenses in the next year and also higher than average, but lower, expenses in the following year. These data are used in more formal estimation to allow extrapolation of this persistence pattern over subsequent years. The formal analysis also shows that the importance of the persistence revealed in mean expenditures appears to be dominated by the enormous variation in expenditure shocks, conditional on any past expenditure pattern.

\section{A "MODEL" OF PERSISTENCE AND EXPENDITURE SHOCKS.}

Our goal is a formal description of medical expenditures that will allow us to simulate the pattern of expenditures over the working life. We begin with a description of the model specification and then explain the simulation procedure. A critical feature of the model is the extent to which it captures actual expenditure patterns and thus we give considerable attention to the model fit. 


\section{A. Specification.}

The descriptive specification must capture two critical features of health care expenditures: (1) the enormous variation across individuals in the same year and (2) the persistence of expenditures from one year to the next. In this version of the analysis we describe annual expenditures. We assume that medical expenditures in year $t, M_{t}$, can be predicted by three factors: demographic characteristics, denoted by $D$, and which include age, sex, and employment status (hourly or salaried); (2) past expenditures $M_{\text {lag, }}$, which in this version include expenditures in years $t-1$ and $t-2$ : and (3) random shocks, $\epsilon$.

$$
\text { (1) } M_{t}=\alpha+\beta D+\gamma M_{\text {lag }}+\epsilon
$$

The critical components are the random shocks and persistence (measured by $\mathrm{y}$ ). Because a large fraction of employees have no expenditures in a given year, it is useful to consider explicitly the expected value of $M$, given by

$$
\text { (2) } E\left(M_{t}\right)=\operatorname{Pr}\left[M_{t} \leq 0\right] \times 0+\operatorname{Pr}\left[M_{t}>0\right] \times E\left(M_{t} \mid M_{t}>0\right)
$$

We estimate the two components -- $\operatorname{Pr}\left[M_{t}>0\right]$, and $E\left(M_{t} \mid M_{t}>0\right)$-- separately. The first is estimated using a linear probability specification, and the second using a log linear regression.

The model estimates, together with exact specifications, are shown in Appendix Table 1. The specification used in the analysis is presented in the 
bottom panel of the table. The basic structure of the specification, however, is more easily seen in the simpler specification that is shown in the top panel. This specification shows three variables (D1, D2, D12) that identify persons with no expenditures in $\mathrm{t}-1$, no expenditures in $\mathrm{t}-2$, and no expenditures in either prior period. Corresponding to these variables are expenditure amounts for persons who had claims in prior years. For example, M1 gives expenditures amounts for persons who had claims in period t-1 (for whom $\mathrm{D} 1=0$ ), and is zero for persons who didn't file a claim in period t-1. For persons with claims in both $\mathrm{t}-1$ and $\mathrm{t}-2$ (the "base" group), there are two expenditure variables, $M^{\star} 1$ and $M^{\star} 2$ for $t-1$ and $t-2$ respectively. The estimated coefficients are difficult to interpret individually. (For example, the coefficient associated with D1 in the simplified expenditure equation $(-0.7485)$ indicates that the expenditure in period $t$ for persons with zero expenditures in both $\mathrm{t}-1$ and $t-2$ is about $75 \%$ lower than the expenditures -- evaluated at $M^{*} 1=M^{*} 2=0$, the "intercept" -- of persons with positive expenditures in both prior periods.) Thus we give scant attention to individual parameter estimates, instead we emphasize below the degree to which the specification reproduces actual expenditure patterns. The more flexible specification relaxes the simplified version in two ways: the lagged expenditures variables are piecewise linear 
and the lagged expenditure variables are interacted with age -- distinguishing persons who are younger from those who are older than 45.

Possibly the most important component of the estimates is the large residual variance. Consider a given a set of right hand variables and the associated mean expenditure. The estimated standard error of the estimate (1.644) suggests that to capture say $95 \%$ of expenditures one would have to cover the range from 0.04 to 27 times the mean.

\section{B. Prediction and Simulation Method.}

The key to prediction is the distribution of random shocks. We want the distribution that is used in prediction to "match" as closely as possible the actual distribution, which is extremely skewed. Here, we use the distribution conditional on the demographic variables $D$ and lagged expenditures. In particular, given $D$ and 25 cells in the five-by-five matrix of $t-1$ and $t-2$ expenditure intervals (used in Table 1), we randomly choose from the distribution of residuals from the two components of equation (2), using a 6year window centered at the age of the person whose expenditures are being predicted. Here, we use the distribution conditional on the demographic variables $D$ and lagged expenditures $M_{\text {lag }}$. This spending history is defined across the 25 cells in the five-by-five matrix of $t-1$ and $t-2$ expenditure intervals used in Table 1. Given $D$ and $M_{\text {lag }}$, we follow this procedure: First, choose a 
residual from the first component of equation 2 conditional on the demographic variables and expenditure history (as reflected by the individual's position in the five-by-five matrix discussed above). If the first component, evaluated at the independent variables and the chosen residual, is greater than 0.5 , the person is considered to have positive expenditures. Second, choose a residual, again conditional on demographics and past spending, from the second component of 2 . Then, predict expenditures using the second component of 2 evaluated at the demographic variables, past spending variables, and the selected shock.

The goal here is not to obtain "behavioral" estimates of marginal effects of predictor variables. Instead, we seek a prediction procedure which captures both the dynamic and cross-section features of health care expenditure over a lifetime. Below, we evaluate how well we have succeeded in attaining this goal.

This initial analysis has at least one potentially important limitation. It assumes that given expenditures in $\mathrm{t}-1$ and $\mathrm{t}-2$, expenditures in prior years add no additional information about expenditures in t. Prior expenditures may, however, contribute additional information and could yield better predictions of persistence. 


\section{The Fit.}

There are at least four ways to check the extent to which the model captures the actual distribution of medical expenditures. All are based on a comparison between simulation results and the actual data. Some of the comparisons emphasize the dynamic properties of our simulation process -the degree to which the simulated expenditures capture the distribution of expense over time. Others emphasize the extent to which the short run model predictions capture the persistence observed in the three-year data panel. We consider the mean of expenditures by age, actual versus predicted expenditure distributions in year $\mathrm{t}$ given expenditures in $\mathrm{t}-1$ and in $\mathrm{t}-2$, actual versus predicted persistence over a three-year period, and the distribution of lifetime predictions at particular ages versus actual distributions at those ages.

1. Actual versus Predicted Means by Age: Figure 4 shows actual and simulated average expenditures by age for hourly and salaried men and women. The actual averages are based on the full sample of 230,497 . The simulated averages are determined as follows: Begin with a sample of 1,000 employees age 25 . Then apply equations (3) repeatedly, producing a stream of expenditures for each person through age 60 . The simulated averages for a given age are the averages of the simulated values at that age. Because the simulated values are based on a rather small number of persons there is 
more variation in the simulated than the actual averages, but the overall match seems quite close. (One might assume that any simple model -- like a Tobit --would yield such a match. But because of the very skewed distributions of health expenditures this is not the case. Indeed, simple Tobit estimates yield means that are at least twice as large as the actual means.)

\section{Actual versus Predicted Third Year Expenditure Distributions:}

Figures $5 a$ through $5 \mathrm{~d}$ show the actual versus predicted distributions of third year (1991) expenditures at selected ages -- 30,40,50, and 60 -- for hourly and salaried men and women. The predicted distribution is based on the demographic variables and expenditures for the first two years (1989 and 1990). Overall, the simulated and actual distributions are very similar.

3. Actual versus Predicted Persistence: Table 2 shows mean actual and simulated expenditures, conditional on the expenditure interval in each of the preceding two years. To illustrate, consider persons 36 to 45 : for employees who had no claims in period $t-1$ and $t-2$, the actual mean expenditure in period $t$ was $\$ 1,295$, compared to a predicted mean of $\$ 1,337$. Overall, the simulated values capture quite well the pattern in the actual data with one exception. For individuals with spending above $\$ 5000$ in both $t-1$ and $t-2$, the prediction of $\$ 11,949$ substantially exceeds the actual value of $\$ 9,934$. Because of the very skewed distribution of shocks, random draws of 
very high shocks in the simulation can have a substantial effect on simulated means.

\section{Distributions of Lifetime Predictions at Selected Ages versus}

Actual Distributions: Our simulations rest on the prediction of the expenditures of employees over a working lifetime. The comparison above suggested that the distribution of the model predictions of third year expenditures were very close to the actual distribution of third year expenditures. Now we consider a comparison that is intended to test the long run implications of the model. We start with the expenditures of a sample of persons who are 25 in 1991 . Then we simulate their expenditures through age 60. We want to know in particular that the distribution of simulated expenditures approximates the actual distribution at older ages. Figures $6 a$ and $6 \mathrm{~b}$ show simulated versus actual distributions at age 45 and 55 . Two comparisons are made: The first compares the simulated distribution at 45 with the distribution of the actual expenditures of persons 45 years old in our sample. The second comparison shows the distribution of simulated and actual cumulated expenditures over three years, ages 45 through 47 . Overall, the distributions of simulated expenditures are very close to actual distributions. Given the small $(1,000)$ sample used for the simulations, simulations based on different samples yield somewhat different comparisons. 
But our experience has been that there is no appreciable difference in the overall results.

5. Other Validation Comparisons. Finally, we considered two additional comparisons to confirm that the persistence implications of the model were consistent with the data. Recall that the model assumes that, given expenditures in $t-1$ and $t-2$, expenditures in prior years add no information about expenditures in year $t$. But although it is likely that there is also some information contained in the pattern of expenditures in previous years, the model lag structure does imply that expenditure shocks will "last" for several years.

First, we considered all persons with high expenditures -- over $\$ 10,000$ and over $\$ 15,000$-- at selected ages -- 35 and 45 -- in 1989. We then used the model to simulate their expenditures in the ten subsequent years. We compared the predictions in the subsequent two years with the actual data. For the first two years, for which we have matching actual data, the actual and simulated means are very close. The lag structure in the model is of course a way to extrapolate the decline in expenditures to future years and the simulations imply that after 4 or 5 years the expenditures of persons with large shocks approach the overall sample mean. The simulated and actual "decay" patterns are shown in Appendix Figure 1. 
Second, we considered the future expenditures of persons with specific 1989 diagnoses that are typically associated with high expenditures. In particular, we were concerned that the expenditure decay in these cases be consistent with the implications of the model. We considered these 1989 diagnosis: AMI, cancer, mental health (with inpatient care), and pregnancy. Only $45 \%$ of 1989 AMI patients had expenditures greater than $\$ 1,000$ one year later in 1990 , only $34 \%$ had expenditures greater than $\$ 1,000$ two years later in 1991. (Over 14\% and zero expenditures in 1990 and 25\% in 1991.) Less than $25 \%$ of cancer patients had expenditures over $\$ 1,000$ in 1990 and only $20 \%$ in 1991 . There was more persistence in the expenditures of Inpatient mental health patients: $54 \%$ had expenditures over $\$ 1,000$ in 1990 and $42 \%$ in 1991. Pregnancy is one of the most important contributors to firm health care costs, but with minimal persistence. Only $17 \%$ of women with pregnancy related diagnosis in 1989 had expenditures over $\$ 1,000$ in 1990 and only $13 \%$ in 1991 . We take these results as evidence that are simulated decay rates are not unreasonable. In particular, we find no reason to suspect that they are too rapid.

We conclude that simulated expenditure patterns compare closely with actual expenditure pattern revealed in the three years of our data. 


\section{SIMULATION RESULTS.}

We have simulated the lifetime expenditures of 1,000 employees who begin work at age 25 and retire at 60 . We realize that few, if any persons, would work for the same firm for that length of time, but it is the expenditure pattern that we want to capture, assuming that employees continued to face an insurance scheme like the one at this firm.

\section{A. The Distribution of Lifetime Expenditures.}

The distribution of cumulative expenditures at selected ages is shown in Figure 7a. Figure 7b shows the concentration version of the data. Over a working lifetime, expenditures of salaried men vary from less than $\$ 10,000$ (about $10 \%$ of employees) to over $\$ 100,000$ (about $10 \%$ of employees). The median is about $\$ 32,000$, as shown in Figure 7a. The distributions for the other gender and employee status groups are similar to those for salaried men.

Figure 7a shows distribution of expenditures is much less concentrated over a lifetime than over 5 years (at age 30). Figure 1 (above) shows that in a single year about $80 \%$ of expenditures are accounted for by about $10 \%$ of employees. For salaried men, Figure $7 b$ shows that after 5 years (at age 30) about $35 \%$ of employees account for $80 \%$ of expenditures. Over a lifetime about $55 \%$ of employees account for $80 \%$ of expenditures. 


\section{B. IHA Balances.}

Given the distribution of expenditures described above, how might an IHA plan work? We consider this plan:

* The employer puts $\$ 2,000$ in each employee's IHA at the beginning of each year.

* The health insurance plan has a $\$ 4,000$ annual deductible, with expenses below the deductible paid by the employee (out of the IHA) and 100 percent of expenditures above the deductible covered by the health insurance plan. If the IHA balance goes to zero, all expenses are paid by the insurance plan.

The distribution of IHA balances at selected ages is shown in Figures 8. Consider salaried men: After 5 years (at age 30 ), about $50 \%$ of men have balances close to $\$ 10,000$. Only about $10 \%$ have balances less than about $\$ 6000$. After a lifetime, there is more variation in the IHA balances, but most employees are left with a substantial accumulation. About $90 \%$ of the employees have a balance at age 60 that exceeds $\$ 25,000$, while $75 \%$ have more than $\$ 40,000$ and $50 \%$ have more than $\$ 50,000$. The distributions are similar for salaried women and for hourly employees.

Another way to understand the plan implications is to consider the proportion of IHA contributions that remain at selected ages. The distributions of these proportions is shown in Figures 9. Two features of the distributions stand out: The fraction declines with age but even at retirement the fraction 
remaining is large for almost all employees. At retirement, only about $20 \%$ of employees have less than $50 \%$ of their contributions, about $10 \%$ have less than $35 \%$, and about $5 \%$ less than $20 \%$. And, $50 \%$ still hold more than $70 \%$ of their IHA contributions.

The average balance remaining in the IHA is shown by age in Figure 10 . The fraction can be compared to the 45 degree line which represents the accumulation path if there were no withdrawals to cover health care costs. The fraction remaining is higher for salaried than for hourly employees and highest for salaried men. The average balance of salaried men is about $\$ 46,000$ at age 60 . The higher average for salaried than for hourly employees may be attributed in large part to differences in plan provisions. The hourly plan provides first-dollar coverage, while the salaried plan includes copayments and a deductible. We have not accounted here for any behavioral effects. If the difference in expenditures of hourly and salaried employees is due to plan provisions, it may be an indication that the behavioral response to a catastrophic plan could be substantial as well.

\section{DISCUSSION.}

A health insurance system featuring IHAs combined with a catastrophic insurance plan would insure employees against high health care costs but 
would also subject a large fraction of expenditures to the discipline imparted by "spending your own money." A potential drawback of this scheme is increased risk, measured by variation in IHA balance accumulation. The variation depends critically on the lifetime distribution of health care costs. With emphasis on this issue, our goal was to present preliminary evidence on the feasibility of an IHA plan.

We developed a non-parametric method to describe the longitudinal distribution of health care expenditures in a large firm. Comparisons with actual firm data suggest that the model captures well the important features of the expenditure distribution. Using this model to simulate the lifetime distribution of individual health care costs, we evaluated the implications of variation in health care expenditures on the variation in IHA balances at retirement. Although the plan would produce a range of balances across employees, approximately $80 \%$ of employees would retain more than $50 \%$ of their IHA contributions. Only about $5 \%$ of employees would retain less than $20 \%$ of their contributions. These outcomes do not appear to us to be so extreme as to make the plan a non-starter.

To say more, we need to incorporate additional components into the analysis. While we believe that such a plan would reduce medical expenses substantially, we must quantify the behavioral response which would occur as 
employees spend more of their own money. Rough calculations suggest that the proportion of payments subject to this restraint would increase from virtually zero to as much as $45 \%$ (depending on whether the payment that pushes the total over the $\$ 4,000$ deductible is counted). And we believe that such a plan could be structured to increase retirement saving. The benefits of reduced health care costs and increased saving must be considered against the risk associated with increased variance in lifetime medical expenditures. Traditional insurance plans which offer near total insurance, and erect a large moral hazard along the way, dampen this variability in lifetime expenditures. By considering risk aversion and time preferences, we can address these tradeoffs more formally in the context of utility analysis.

An IHA plan could have important implications for the composition and, possibly, the level of employee compensation. The overall annual cost of the firm's current health plan is around $\$ 1,400$ per participant. With no behavioral effects, the IHA plan we consider would reduce this premium to around $\$ 700$ per participant. Employee health care costs would increase by about $\$ 700$. Assuming no reduction in other non-wage benefits, the IHA contribution of $\$ 2,000$ would result in a net increase in total employee benefits of approximately $\$ 1,300$. Evidence on $401(k)$ plans suggests that offsetting effects on other employee benefits is unclear. Many $401(k)$ plans were 
established with no apparent reductions in other components of employee compensation, at least in the short run.

The actual additional cost to be divided between the firm and its employees may be substantially lessened not only by any behavioral effect, but also by the favorable tax treatment accorded to $401(\mathrm{k})$ and other retirement programs, as well as health insurance premiums. For example, if contributions to an IHA were also treated in this manner and perhaps combined with a retirement savings program, copayments and deductibles now made by employees with after-tax earnings might be replaced by payments made in pre-tax earnings from an IHA account.

We also need to explore variations in the structure of IHA plans to understand the implications of alternative IHA contributions, savings accumulations, and out-of-pocket expenditures. Our analysis reveals that small changes in the structure of the plan can substantially alter the "way the numbers look." For example, if the IHA contribution is made at the end of the year -- and thus is not available to fund expenditures in the current year -virtually no one would be left with IHA accumulations less than $35 \%$ to $40 \%$ of their contributions (although this would generate a somewhat higher insurance premium). The results would also look quite different if IHA contribution were $\$ 1,000$ instead of $\$ 2,000$. 
We intend to consider all these issues more thoroughly in future work. We also plan to re-estimate the parameters of our model with longer panels of expenditure data when they become available, and to consider other kinds of health plan reforms from the perspective of lifetime expenditures. 


\section{REFERENCES}

Arrow, Kenneth J. 1963. "Uncertainty and the Welfare Economics of Medical Care." American Economic Review 53:941-973

Feldstein, Martin. 1971. "A New Approach to National Health Insurance." The Public Interest 23:93-105.

Feldstein, Martin and Jonathan Gruber. 1994. "A Major Risk Approach to Health Insurance Reform." NBER Working Paper No. 4852.

McClellan, Mark B. and David A. Wise. 1994. "Where the Money Goes:

Medical Expenditures in a Large Corporation." Prepared for the JCERNBER Conference on Health Care, December. 


\begin{tabular}{|c|c|c|c|c|c|c|}
\hline \multirow{2}{*}{ Age } & \multirow{2}{*}{$\begin{array}{c}1989 \\
\text { Expenditure }\end{array}$} & \multicolumn{5}{|c|}{1990 Expenditure } \\
\hline & & $\$ 0$ & $\$ 0-\$ 300$ & $\$ 300-\$ 1000$ & $\$ 1000-\$ 5000$ & Above $\$ 5000$ \\
\hline \multirow[t]{5}{*}{$0-17$} & $\$ 0$ & 43.9 & 37.25 & 11.42 & 5.57 & 1.86 \\
\hline & $\$ 0-\$ 300$ & 45.4 & 34.84 & 12.56 & 5.75 & 1.44 \\
\hline & $\$ 300-\$ 1000$ & 29 & 32.32 & 22.97 & 12.19 & 3.52 \\
\hline & $\$ 1000-\$ 5000$ & 28.1 & 25.69 & 20.92 & 19.05 & 6.25 \\
\hline & Above $\$ 5000$ & 23.28 & 19.32 & 17.43 & 20.76 & 19.21 \\
\hline \multirow[t]{5}{*}{ 18-35 } & $\$ 0$ & 40.94 & 33.97 & 12.92 & 8.25 & 3.92 \\
\hline & $\$ 0-\$ 300$ & 51.62 & 26.57 & 11.36 & 7.27 & 3.19 \\
\hline & $\$ 300-\$ 1000$ & 35.55 & 25.5 & 18.76 & 13.69 & 6.51 \\
\hline & $\$ 1000-\$ 5000$ & 32.9 & 20.93 & 17.12 & 19 & 10.05 \\
\hline & Above $\$ 5000$ & 29.17 & 17.36 & 14.76 & 17.92 & 20.79 \\
\hline \multirow[t]{5}{*}{$36-45$} & $\$ 0$ & 40.27 & 33.06 & 13.6 & 8.65 & 4.41 \\
\hline & $\$ 0-\$ 300$ & 36.57 & 33.03 & 16.11 & 10.12 & 4.18 \\
\hline & $\$ 300-\$ 1000$ & 23.93 & 26.83 & 24.07 & 18.25 & 6.92 \\
\hline & $\$ 1000-\$ 5000$ & 18.88 & 19.97 & 21.19 & 27.93 & 12.04 \\
\hline & Above $\$ 5000$ & 18.63 & 16.82 & 16.67 & 22.81 & 25.07 \\
\hline \multirow[t]{5}{*}{$46-55$} & $\$ 0$ & 37.65 & 32.14 & 14.52 & 10.15 & 5.53 \\
\hline & $\$ 0-\$ 300$ & 30.99 & 34.29 & 17.9 & 11.61 & 5.21 \\
\hline & $\$ 300-\$ 1000$ & 17.84 & 26.35 & 28.2 & 19.47 & 8.13 \\
\hline & $\$ 1000-\$ 5000$ & 15.59 & 19.55 & 22.41 & 28.76 & 13.7 \\
\hline & Above $\$ 5000$ & 14.41 & 15.73 & 16.88 & 24.38 & 28.6 \\
\hline \multirow[t]{5}{*}{$56-65$} & $\$ 0$ & 31.14 & 34.73 & 15.64 & 10.89 & 7.6 \\
\hline & $\$ 0-\$ 300$ & 35.87 & 31.89 & 16.52 & 10.14 & 5.58 \\
\hline & $\$ 300-\$ 1000$ & 22.62 & 24.54 & 26.68 & 17.36 & 8.8 \\
\hline & $\$ 1000-\$ 5000$ & 19.17 & 18.87 & 21.66 & 26.07 & 14.23 \\
\hline & Above $\$ 5000$ & 21.5 & 13.82 & 15.67 & 22.42 & 26.6 \\
\hline
\end{tabular}




\begin{tabular}{|c|c|c|c|c|c|c|}
\hline \multirow{3}{*}{ Age } & \multicolumn{6}{|c|}{$\begin{array}{c}\text { Table 1. Percent Distribution of } 1990 \text { and } 1991 \text { Expenditures, } \\
\text { by } 1989 \text { Expenditure Interval and by Age }\end{array}$} \\
\hline & \multirow{2}{*}{$\begin{array}{c}1989 \\
\text { Expenditure }\end{array}$} & \multicolumn{5}{|c|}{1991 Expenditure } \\
\hline & & $\$ 0$ & $\$ 0-\$ 300$ & $\$ 300-\$ 1000$ & $1000-\$ 5$ & Above $\$ 5000$ \\
\hline \multirow[t]{5}{*}{$0-17$} & $\$ 0$ & 28.29 & 46.98 & 14.87 & 7.49 & 2.37 \\
\hline & $\$ 0-\$ 300$ & 51.94 & 29.34 & 11.47 & 5.67 & 1.58 \\
\hline & $\$ 300-\$ 1000$ & 38.92 & 28.29 & 19.03 & 10.31 & 3.45 \\
\hline & $\$ 1000-\$ 5000$ & 39.44 & 23.35 & 17.52 & 14.47 & 5.22 \\
\hline & Above $\$ 5000$ & 38.65 & 18.18 & 17.43 & 14.11 & 11.64 \\
\hline \multirow[t]{5}{*}{$18-35$} & $\$ 0$ & 28.57 & 39.13 & 15.95 & 10.81 & 5.53 \\
\hline & $\$ 0-\$ 300$ & 63.58 & 19.21 & 8.98 & 5.54 & 2.69 \\
\hline & $\$ 300-\$ 1000$ & 52.13 & 18.86 & 14 & 10.26 & 4.75 \\
\hline & $\$ 1000-\$ 5000$ & 48.7 & 16.2 & 13.49 & 14.87 & 6.73 \\
\hline & Above $\$ 5000$ & 46.32 & 13.9 & 11.17 & 13.69 & 14.92 \\
\hline \multirow[t]{5}{*}{$36-45$} & $\$ 0$ & 24.43 & 40.28 & 17.38 & 11.98 & 5.91 \\
\hline & $\$ 0-\$ 300$ & 40.43 & 29.4 & 15.88 & 9.83 & 4.46 \\
\hline & $\$ 300-\$ 1000$ & 31.02 & 24.29 & 21.79 & 15.94 & 6.96 \\
\hline & $\$ 1000-\$ 5000$ & 26.95 & 18.88 & 20.37 & 23.77 & 10.03 \\
\hline & Above $\$ 5000$ & 27.19 & 16.51 & 15.15 & 20.3 & 20.86 \\
\hline \multirow[t]{5}{*}{$46-55$} & $\$ 0$ & 23.23 & 37.97 & 17.87 & 13.13 & 7.79 \\
\hline & $\$ 0-\$ 300$ & 32.73 & 31.41 & 17.85 & 11.89 & 6.13 \\
\hline & $\$ 300-\$ 1000$ & 21.86 & 24.75 & 26.06 & 18.54 & 8.79 \\
\hline & $\$ 1000-\$ 5000$ & 20.33 & 19.27 & 20.69 & 26.75 & 12.95 \\
\hline & Above $\$ 5000$ & 22.66 & 15.85 & 16.05 & 23.6 & 21.83 \\
\hline \multirow[t]{5}{*}{$56-65$} & $\$ 0$ & 29.58 & 33.78 & 16.54 & 11.92 & 8.18 \\
\hline & $\$ 0-\$ 300$ & 44.32 & 25.3 & 14.75 & 9.7 & 5.93 \\
\hline & $\$ 300-\$ 1000$ & 34.87 & 19.25 & 21.41 & 15.85 & 8.62 \\
\hline & $\$ 1000-\$ 5000$ & 31.96 & 15.95 & 18.28 & 21.31 & 12.5 \\
\hline & Above $\$ 5000$ & 38.09 & 13 & 12.46 & 18.33 & 18.13 \\
\hline
\end{tabular}




\begin{tabular}{|c|c|c|c|c|c|}
\hline \multirow{2}{*}{$\begin{array}{c}\text { Expenditure in } \\
1989\end{array}$} & \multicolumn{5}{|c|}{ Expenditure in 1990} \\
\hline & $\$ 0$ & $<\$ 300$ & $\$ 300-\$ 100$ & $000-\$ 5000$ & $>\$ 5000$ \\
\hline \multicolumn{6}{|c|}{ Enrollees Aged 36-45 } \\
\hline \multicolumn{6}{|c|}{ Actual Mean for 1990} \\
\hline$\$ 0$ & $\$ 1,295$ & $\$ 742$ & $\$ 1,162$ & $\$ 1,677$ & $\$ 4,383$ \\
\hline$<\$ 300$ & $\$ 435$ & $\$ 761$ & $\$ 1,130$ & $\$ 1,732$ & $\$ 3,584$ \\
\hline$\$ 300-\$ 1000$ & $\$ 607$ & $\$ 825$ & $\$ 1,452$ & $\$ 2,334$ & $\$ 4,390$ \\
\hline$\$ 1000-\$ 5000$ & $\$ 697$ & $\$ 1,154$ & $\$ 1,719$ & $\$ 2,449$ & $\$ 4,178$ \\
\hline$>\$ 5000$ & $\$ 844$ & $\$ 1,811$ & $\$ 2,175$ & $\$ 4,003$ & $\$ 9,934$ \\
\hline \multicolumn{6}{|c|}{ Predicted Mean for 1990} \\
\hline$\$ 0$ & $\$ 1,337$ & $\$ 727$ & $\$ 1,206$ & $\$ 1,828$ & $\$ 4,153$ \\
\hline$<\$ 300$ & $\$ 459$ & $\$ 780$ & $\$ 1,199$ & $\$ 1,797$ & $\$ 3,751$ \\
\hline$\$ 300-\$ 1000$ & $\$ 639$ & $\$ 776$ & $\$ 1,419$ & $\$ 2,507$ & $\$ 5,903$ \\
\hline$\$ 1000-\$ 5000$ & $\$ 1,206$ & $\$ 1,386$ & $\$ 1,847$ & $\$ 2,543$ & $\$ 4,659$ \\
\hline$>\$ 5000$ & $\$ 1,014$ & $\$ 1,727$ & $\$ 2,281$ & $\$ 3,991$ & $\$ 11,949$ \\
\hline \multicolumn{6}{|c|}{ Enrollees Aged 46-55 } \\
\hline \multicolumn{6}{|c|}{ Actual Mean for 1991} \\
\hline$\$ 0$ & $\$ 1,718$ & $\$ 1,042$ & $\$ 1,471$ & $\$ 2,132$ & $\$ 4,854$ \\
\hline$<\$ 300$ & $\$ 725$ & $\$ 1,038$ & $\$ 1,490$ & $\$ 2,066$ & $\$ 4,238$ \\
\hline$\$ 300-\$ 1000$ & $\$ 819$ & $\$ 1,589$ & $\$ 1,882$ & $\$ 2,398$ & $\$ 5,267$ \\
\hline$\$ 1000-\$ 5000$ & $\$ 950$ & $\$ 1,564$ & $\$ 2,223$ & $\$ 3,413$ & $\$ 6,377$ \\
\hline$>\$ 5000$ & $\$ 1,593$ & $\$ 2,069$ & $\$ 2,965$ & $\$ 4,327$ & $\$ 10,380$ \\
\hline \multicolumn{6}{|c|}{ Predicted Mean for 1991} \\
\hline$\$ 0$ & $\$ 1,739$ & $\$ 991$ & $\$ 1,477$ & $\$ 1,998$ & $\$ 5,824$ \\
\hline$<\$ 300$ & $\$ 691$ & $\$ 1,094$ & $\$ 1,554$ & $\$ 2,364$ & $\$ 4,163$ \\
\hline$\$ 300-\$ 1000$ & $\$ 695$ & $\$ 1,674$ & $\$ 1,729$ & $\$ 2,440$ & $\$ 4,809$ \\
\hline$\$ 1000-\$ 5000$ & $\$ 1,086$ & $\$ 1,524$ & $\$ 2,076$ & $\$ 3,459$ & $\$ 7,031$ \\
\hline$>\$ 5000$ & $\$ 3,253$ & $\$ 1,642$ & $\$ 3,343$ & $\$ 4,545$ & $\$ 13,012$ \\
\hline
\end{tabular}




\begin{tabular}{|c|c|c|c|c|}
\hline \multicolumn{5}{|c|}{ Appendix Table 1. Model Parameter Estimates } \\
\hline \multirow{2}{*}{ Variable } & \multicolumn{2}{|c|}{ Linear Probability } & \multicolumn{2}{|c|}{ Log-Linear if \$Amount $>0$} \\
\hline & Estimate & T-Statistic & Estimate & T-Statistic \\
\hline \multicolumn{5}{|c|}{ Simplified Specification } \\
\hline Constant & 0.831471 & 130.294065 & 5.968484 & 177.958314 \\
\hline Age & -0.001120 & -9.105254 & 0.007943 & 12.126717 \\
\hline Sex & 0.044624 & 5.543992 & 0.207343 & 4.951444 \\
\hline$($ Age $)($ Sex $)$ & -0.000237 & -1.441283 & -0.003874 & -4.481654 \\
\hline Hourly & -0.023953 & -12.092770 & -0.027556 & -2.862969 \\
\hline D1 & -0.449010 & -184.611500 & -0.542924 & -33.122375 \\
\hline D2 & -0.183226 & -73.009823 & -0.302466 & -23.604705 \\
\hline D12 & 0.203681 & 69.794990 & -0.748530 & -60.388999 \\
\hline M1 & 0.000004 & 14.447127 & 0.000043 & 30.102726 \\
\hline M2 & -0.000003 & -13.460566 & 0.000041 & 9.894052 \\
\hline$M^{* 1}$ & 0.000001 & 10.385432 & 0.000040 & 60.611868 \\
\hline$M^{\star} 2$ & -0.000000 & -2.210547 & 0.000028 & 37.152903 \\
\hline
\end{tabular}




\begin{tabular}{|c|c|c|c|c|}
\hline \multicolumn{5}{|c|}{ Appendix Table 1. Model Parameter Estimates } \\
\hline \multirow{2}{*}{ Variable } & \multicolumn{2}{|c|}{ Linear Probability } & \multicolumn{2}{|c|}{ Log-Linear if $\$$ Amount $>0$} \\
\hline & Estimate & T-Statistic & Estimate & T-Statistic \\
\hline \multicolumn{5}{|c|}{ Piecewise Linear with Age Interaction } \\
\hline Constant & 0.767076 & 76.081033 & 5.218912 & 102.262185 \\
\hline Age & -0.005531 & -31.751904 & 0.001529 & 1.688721 \\
\hline Sex & 0.038068 & 4.781396 & 0.199626 & 4.886164 \\
\hline$($ Age)(Sex) & -0.000180 & -1.105580 & -0.004235 & -5.019273 \\
\hline Hourly & -0.017851 & -9.112001 & -0.001713 & -0.182322 \\
\hline D1 & -0.267524 & -28.154423 & 0.078253 & 1.357532 \\
\hline D2 & -0.072295 & -7.645898 & 0.138964 & 2.828726 \\
\hline D12 & 0.421501 & 54.552813 & 0.200218 & 5.465471 \\
\hline M1 & 0.000407 & 11.373989 & 0.001937 & 10.145843 \\
\hline $\mathrm{M}_{300}$ & -0.000308 & -6.716501 & -0.001345 & -5.583627 \\
\hline$M 1_{1000}$ & -0.000097 & -7.018825 & -0.000560 & -8.153725 \\
\hline $\mathrm{M} 2$ & 0.000223 & 5.931243 & 0.001604 & 6.105962 \\
\hline $\mathrm{M} 2_{300}$ & -0.000256 & -5.280451 & -0.001434 & -4.221094 \\
\hline$M 2_{1000}$ & 0.000030 & 1.989208 & -0.000157 & -1.449693 \\
\hline$M^{* 1}$ & 0.000529 & 19.042785 & 0.001386 & 10.339624 \\
\hline$M^{*} 1_{300}$ & -0.000441 & -12.932473 & -0.000490 & -3.015251 \\
\hline$M^{\star} 1_{1000}$ & -0.000088 & -9.944736 & -0.000868 & -21.430002 \\
\hline$M^{\star} 2$ & 0.000183 & 6.669677 & 0.000811 & 6.275513 \\
\hline$M^{\star} 2_{300}$ & -0.000171 & -5.061111 & -0.000228 & -1.444769 \\
\hline$M * 2_{1000}$ & -0.000013 & -1.448336 & -0.000562 & -13.744969 \\
\hline Age45 & 0.131443 & 14.109861 & 0.071001 & 1.571068 \\
\hline (D1)(Age45) & -0.016230 & -1.306935 & 0.132904 & 1.749148 \\
\hline (D2)(Age45) & -0.035120 & -2.738827 & 0.091063 & 1.360564 \\
\hline (D12)(Age45) & -0.043627 & -4.236622 & 0.099796 & 2.078911 \\
\hline$(\mathrm{M} 1)(\mathrm{Age} 45)$ & 0.000055 & 1.075926 & -0.000170 & -0.622411 \\
\hline$(\mathrm{M} 1300)(\mathrm{Age} 45)$ & -0.000063 & -0.963313 & 0.000211 & 0.616798 \\
\hline$\left(\mathrm{M} 1_{1000}\right)(\mathrm{Age} 45)$ & 0.000006 & 0.310614 & -0.000046 & -0.479565 \\
\hline (M2)(Age45) & -0.000079 & -1.587965 & -0.000168 & -0.477427 \\
\hline$\left(\mathrm{M2}_{300}\right)(\mathrm{Age} 45)$ & 0.000066 & 1.027559 & 0.000211 & 0.463816 \\
\hline$\left(\mathrm{M}_{1000}\right)($ Age 45$)$ & 0.000014 & 0.709447 & -0.000034 & -0.239341 \\
\hline$\left(M^{*} 1\right)(A g e 45)$ & 0.000047 & 1.335356 & 0.000065 & 0.381546 \\
\hline$\left(M^{*} 1_{300}\right)(A g e 45)$ & -0.000070 & -1.623723 & -0.000028 & -0.136822 \\
\hline$\left(\mathrm{M}^{*} 1_{1000}\right)($ Age 45$)$ & 0.000022 & 2.014475 & -0.000041 & -0.809818 \\
\hline$\left(M^{*} 2\right)($ Age 45$)$ & -0.000006 & -0.168130 & 0.000305 & 1.868320 \\
\hline$\left(\mathrm{M}^{\star} 2_{300}\right)(\mathrm{Age} 45)$ & -0.000014 & -0.317268 & -0.000340 & -1.710830 \\
\hline$\left(M^{*} 2_{100}\right)($ Age45) & 0.000019 & 1.673649 & 0.000025 & 0.494918 \\
\hline
\end{tabular}




\begin{tabular}{|c|c|}
\hline \multicolumn{2}{|r|}{ Variable Definitions, Appendix Table 1} \\
\hline \\
\hline \multicolumn{2}{|r|}{ 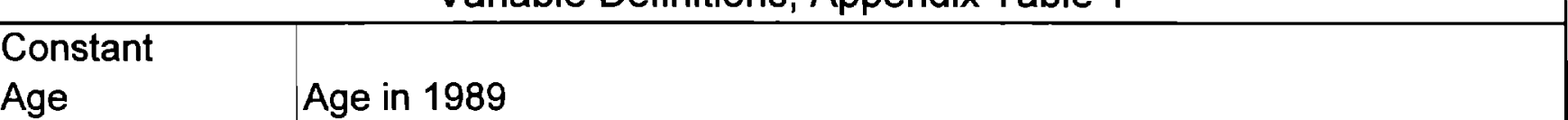 } \\
\hline Sex & 1 if Female; 0 otherwise \\
\hline$($ Age $)($ Sex $)$ & Age interacted with Sex \\
\hline Hourly & 1 if Hourly worker; 0 otherwise \\
\hline D1 & 1 if no expenditures in period $t-1 ; 0$ otherwise \\
\hline $\mathrm{D} 2$ & 1 if no expenditures in period $t-2 ; 0$ otherwise \\
\hline D12 & 1 if no expenditures in periods $t-1$ and $t-2 ; 0$ otherwise \\
\hline M1 & Expenditure in $\mathrm{t}-1$ if no expenditure in $\mathrm{t}-2$ \\
\hline $\mathrm{M}_{3}{ }_{300}$ & $\begin{array}{l}\text { Expenditure in } t-1 \text { minus } 300 \text { if no expenditure in } t-2 \text { and expenditure in } t \\
-1 \text { above } 300\end{array}$ \\
\hline$M 1_{1000}$ & $\begin{array}{l}\text { Expenditure in } t-1 \text { minus } 1000 \text { if no expenditure in } t-2 \text { and expenditure in } \\
t-1 \text { above } 1000\end{array}$ \\
\hline M2 & Expenditure in $\mathrm{t}-2$ if no expenditure in $\mathrm{t}-1$ \\
\hline $\mathrm{M}_{300}$ & $\begin{array}{l}\text { Expenditure in } \mathrm{t}-2 \text { minus } 300 \text { if no expenditure in } \mathrm{t}-1 \text { and expenditure in } \\
\mathrm{t}-2\end{array}$ \\
\hline$M 2_{1000}$ & $\begin{array}{l}\text { Expenditure in } t-2 \text { minus } 1000 \text { if no expenditure in } t-1 \text { and expenditure in } \\
t-2 \text { above } 1000\end{array}$ \\
\hline$M^{*} 1$ & Expenditure in $\mathrm{t}-1$ if expenditure in both $\mathrm{t}-1$ and $\mathrm{t}-2$ \\
\hline$M^{*} 1_{300}$ & $\begin{array}{l}\text { Expenditure in } \mathrm{t}-1 \text { minus } 300 \text { if expenditure in both } \mathrm{t}-1 \text { and } \mathrm{t}-2 \text { and } \\
\text { expenditure in } \mathrm{t}-1 \text { above } 300\end{array}$ \\
\hline$M^{*} 1_{1000}$ & $\begin{array}{l}\text { Expenditure in } t-1 \text { minus } 1000 \text { if expenditure in both } t-1 \text { and } t-2 \text { and } \\
\text { expenditure in } t-1 \text { above } 1000\end{array}$ \\
\hline$M \star 2$ & Expenditure in $\mathrm{t}-2$ if expenditure in both $\mathrm{t}-1$ and $\mathrm{t}-2$ \\
\hline$M^{\star} 2_{300}$ & $\begin{array}{l}\text { Expenditure in } \mathrm{t}-2 \text { minus } 300 \text { if expenditure in both } \mathrm{t}-1 \text { and } \mathrm{t}-2 \text { and } \\
\text { expenditure in } \mathrm{t}-2 \text { above } 300\end{array}$ \\
\hline$M^{\star} 2_{1000}$ & $\begin{array}{l}\text { Expenditure in } t-2 \text { minus } 1000 \text { if expenditure in both } t-1 \text { and } t-2 \text { and } \\
\text { expenditure in } t-2 \text { above } 1000\end{array}$ \\
\hline \multirow{2}{*}{$\begin{array}{l}\text { Age45 } \\
\text { (D1)(Age45) }\end{array}$} & 1 if age in 1989 above $45 ; 0$ otherwise \\
\hline & D1 interacted with Age45 \\
\hline (D2)(Age45) & D2 interacted with Age45 \\
\hline (D12)(Age45) & D12 interacted with Age45 \\
\hline (M1)(Age45) & M1 interacted with Age45 \\
\hline$\left(\mathrm{M1}_{300}\right)(\mathrm{Age} 45)$ & $\mathrm{M}_{300}$ interacted with Age45 \\
\hline \multirow{2}{*}{$\begin{array}{l}\left(\mathrm{M} 1_{1000}\right)(\mathrm{Age} 45) \\
(\mathrm{M} 2)(\text { Age45) }\end{array}$} & $\mathrm{M} 1_{1000}$ interacted with Age45 \\
\hline & M2 interacted with Age45 \\
\hline \multirow{2}{*}{$\begin{array}{l}\left(\mathrm{M} 2_{300}\right)(\text { Age } 45) \\
\left(\mathrm{M} 2_{1000}\right)(\text { Age45) }\end{array}$} & $\mathrm{M} 2_{300}$ interacted with Age45 \\
\hline & M2 1000 interacted with Age45 \\
\hline$\left(M^{* 1}\right)($ Age 45) & $M^{* 1}$ interacted with Age45 \\
\hline \multirow{3}{*}{$\begin{array}{l}\left(\mathrm{M}^{*} 1_{300}\right)(\mathrm{Age} 45) \\
\left(\mathrm{M}^{*} 1_{1000}\right)(\mathrm{Age} 45) \\
\left(\mathrm{M}^{*} 2\right)(\mathrm{Age} 45)\end{array}$} & $\mathrm{M}^{*} 1_{300}$ interacted with Age45 \\
\hline & $\mathrm{M}^{*} 1_{1000}$ interacted with Age45 \\
\hline & $M^{\star} 2$ interacted with Age45 \\
\hline \multirow{2}{*}{$\begin{array}{l}\left(M^{*} 2_{300}\right)(\text { Age } 45) \\
\left(M^{*} 2_{1000}\right)(\text { Age45) }\end{array}$} & $M^{\star} 2_{300}$ interacted with Age45 \\
\hline & $M^{\star} 2_{1000}$ with Age45 \\
\hline
\end{tabular}




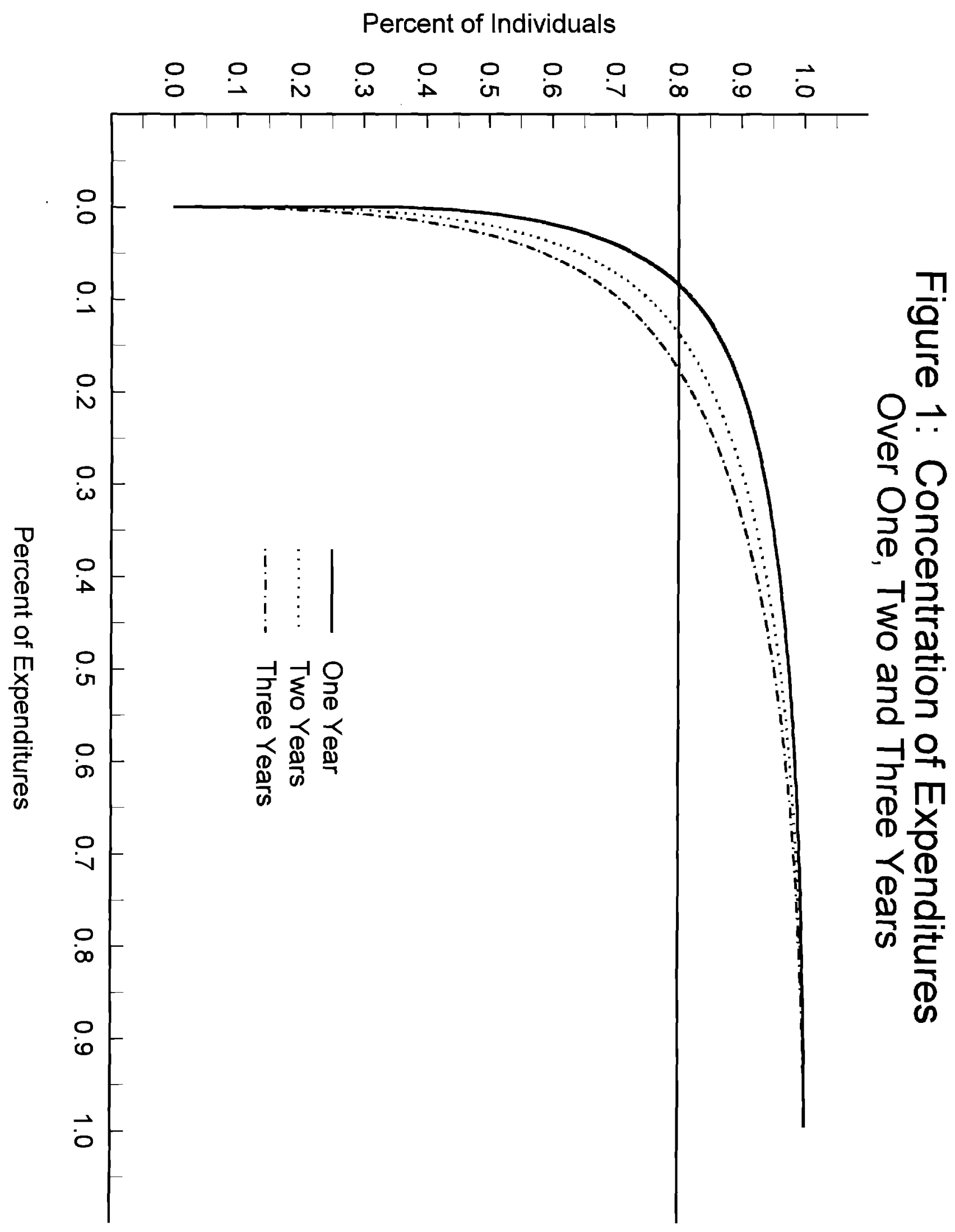




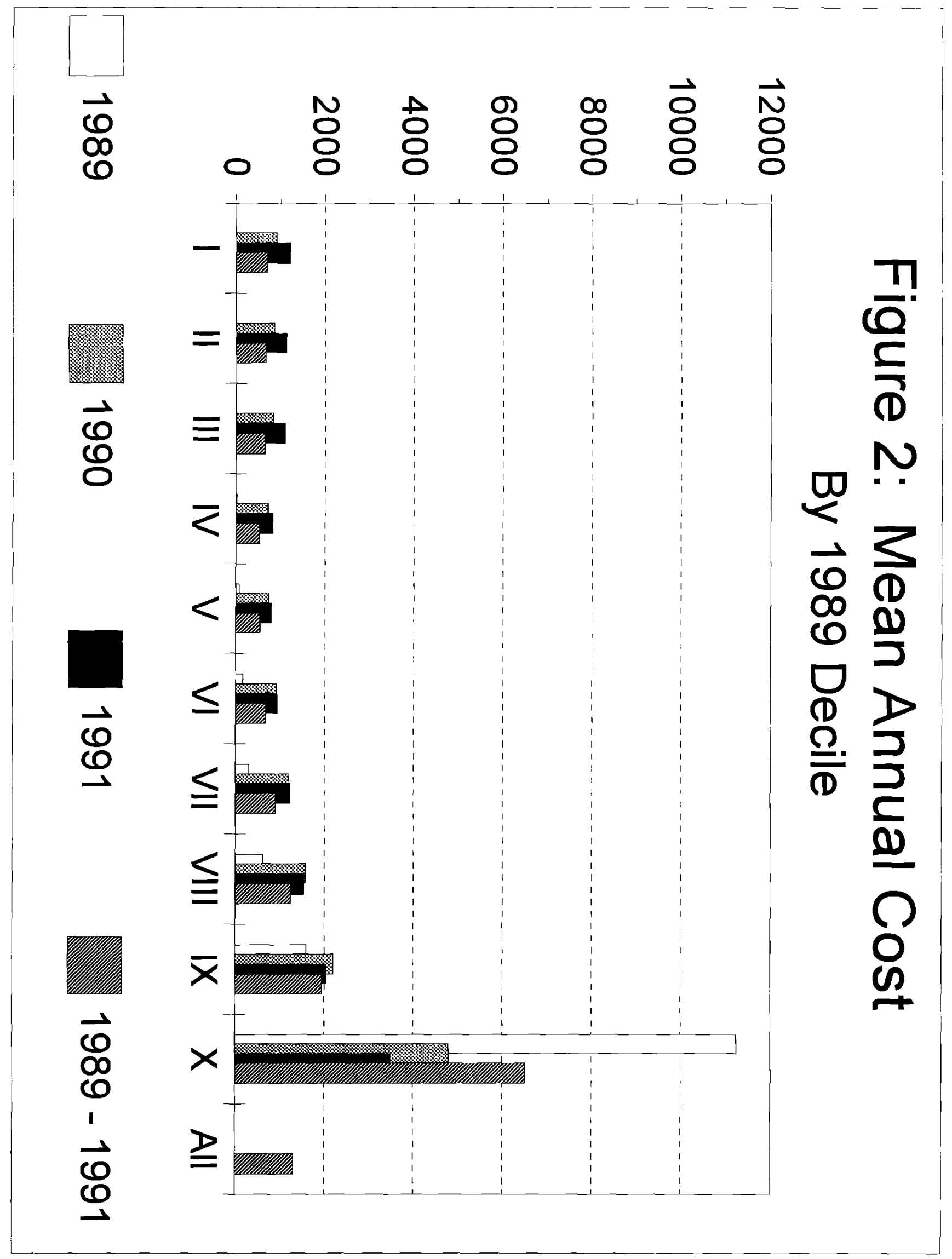




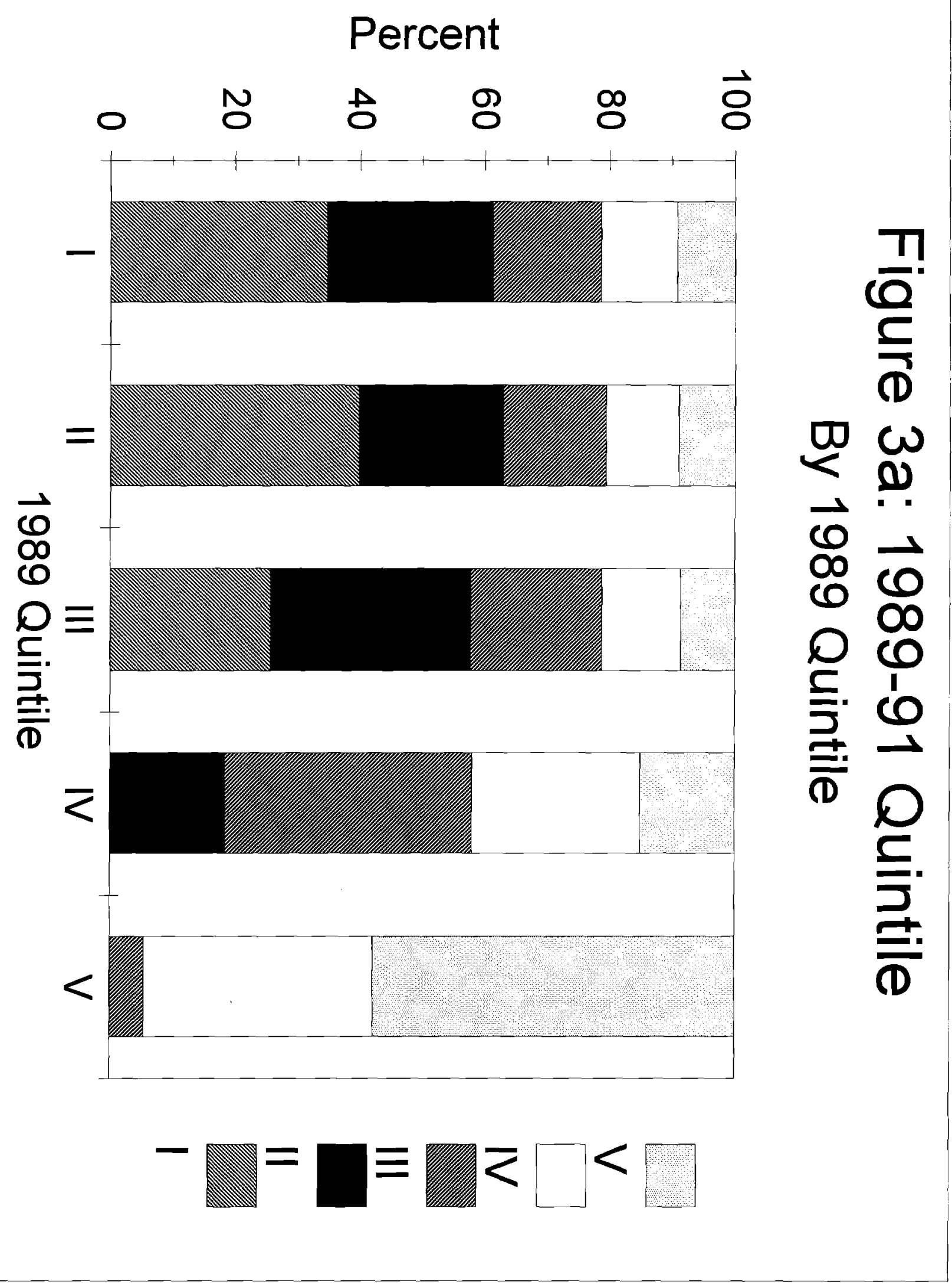




\section{Percent}

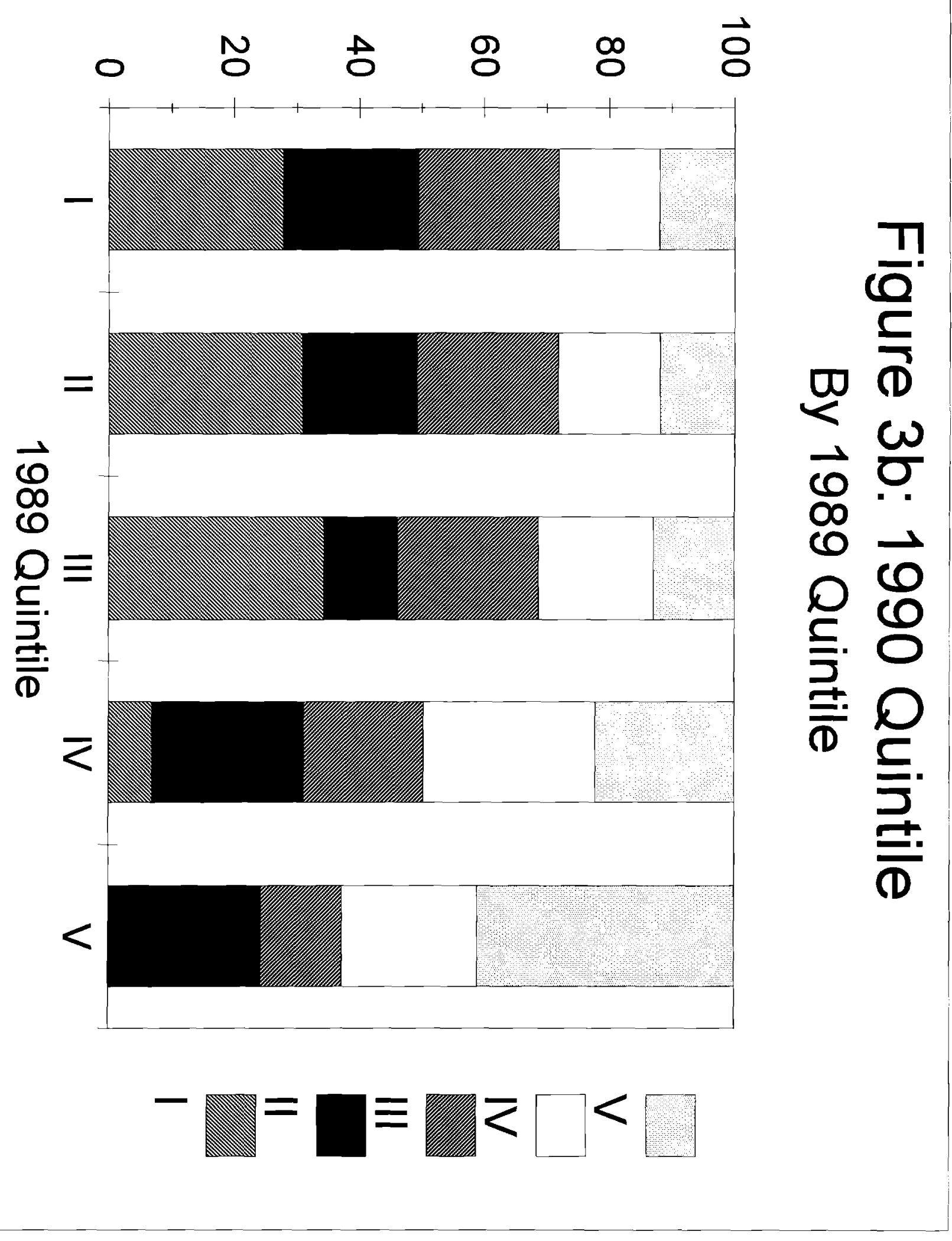




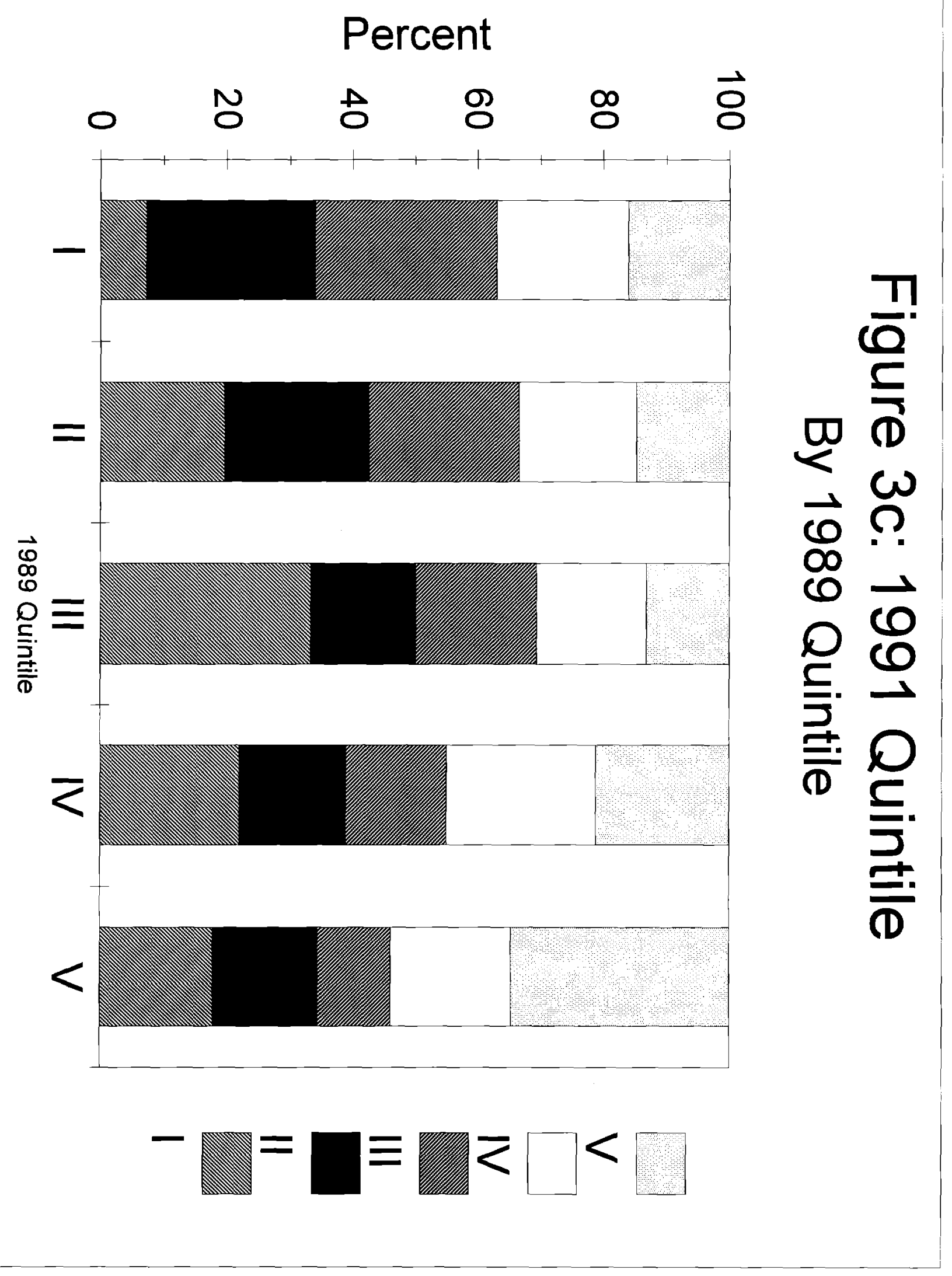



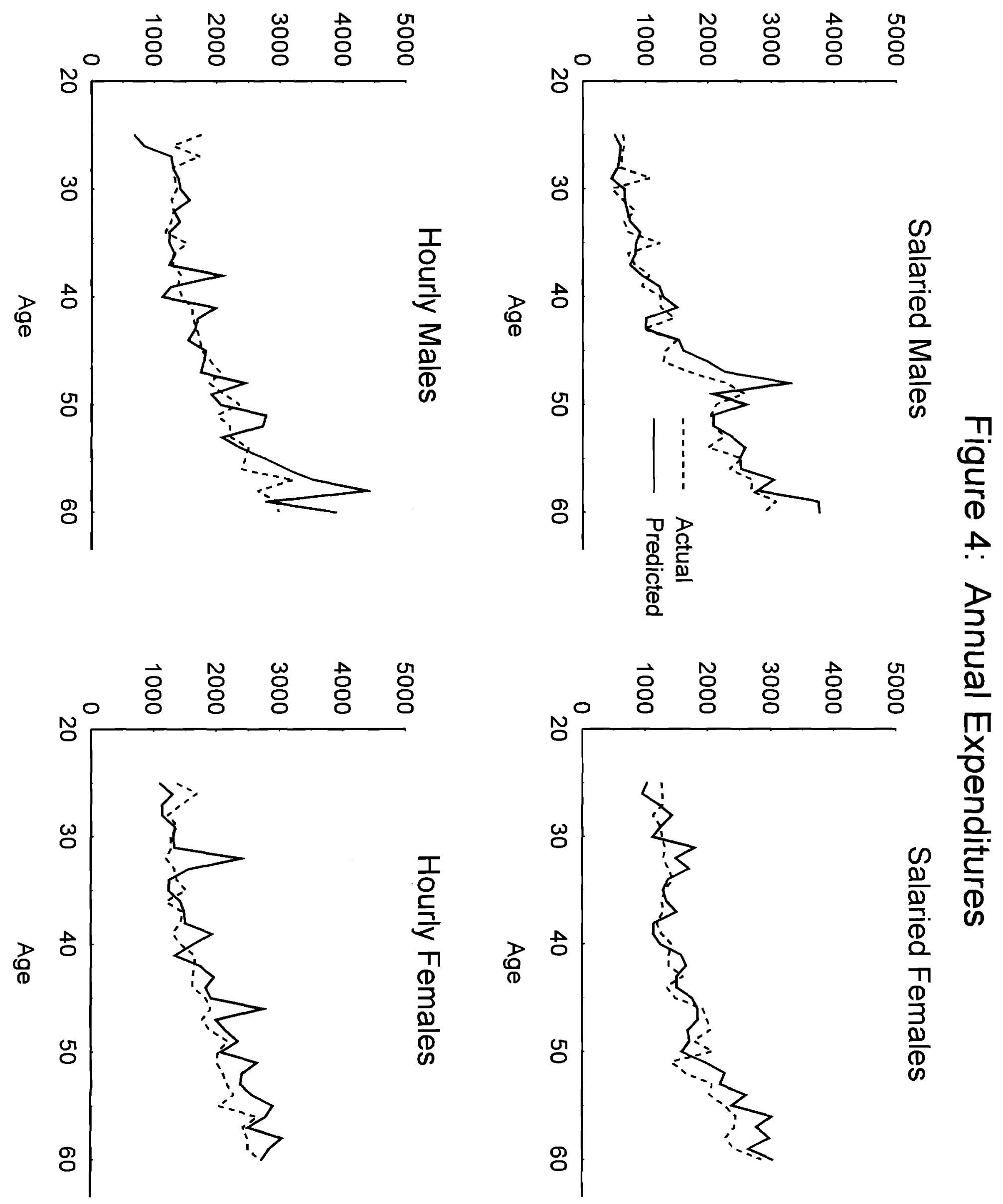

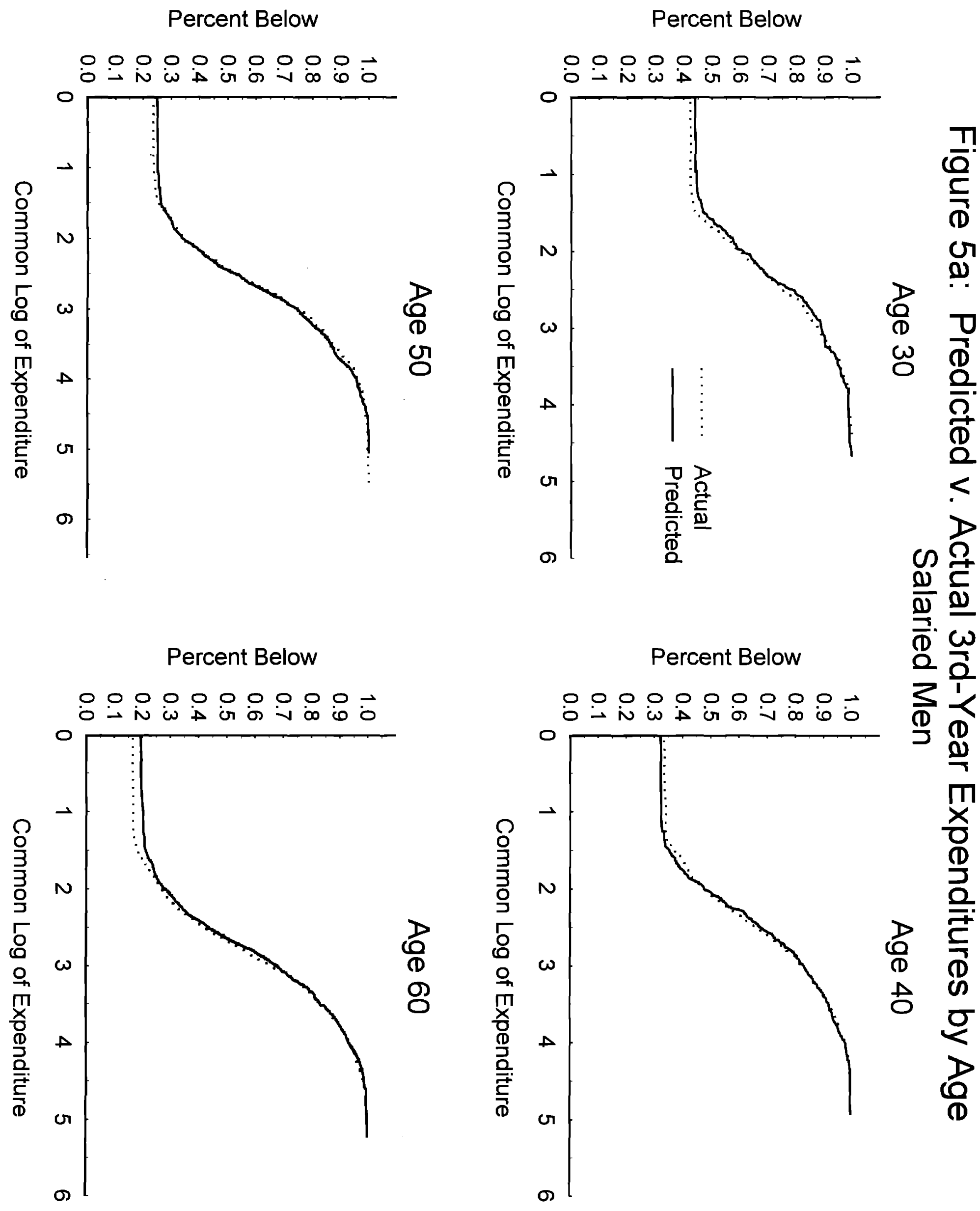
Percent Below
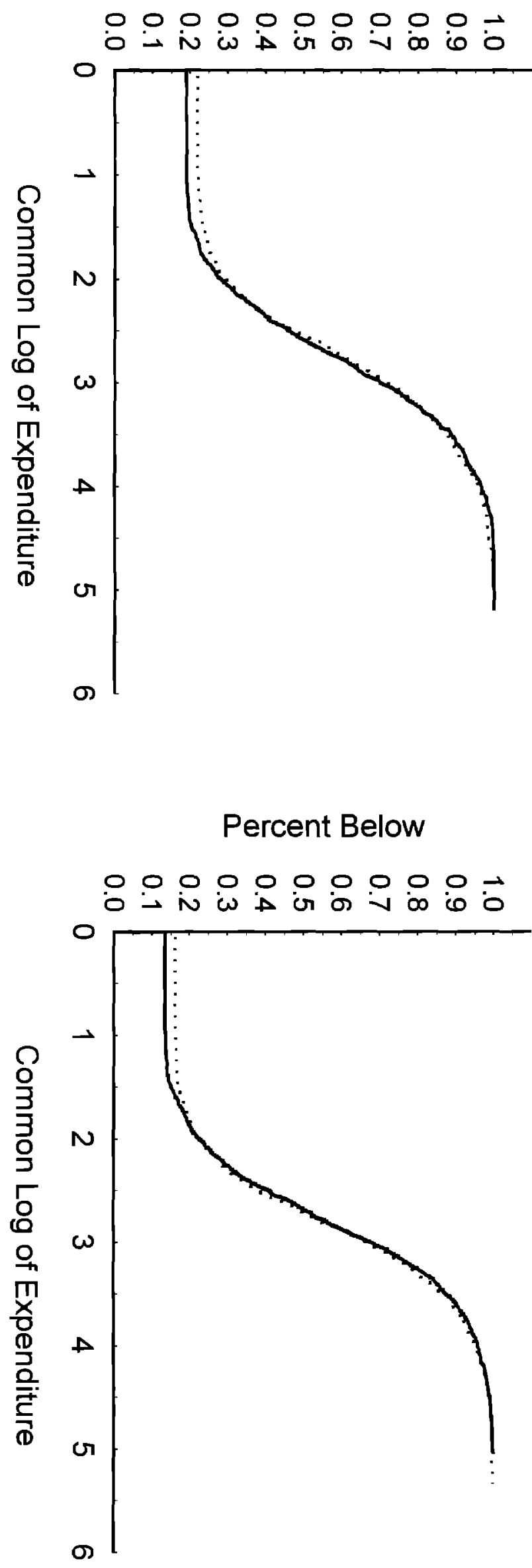

\section{Percent Below}
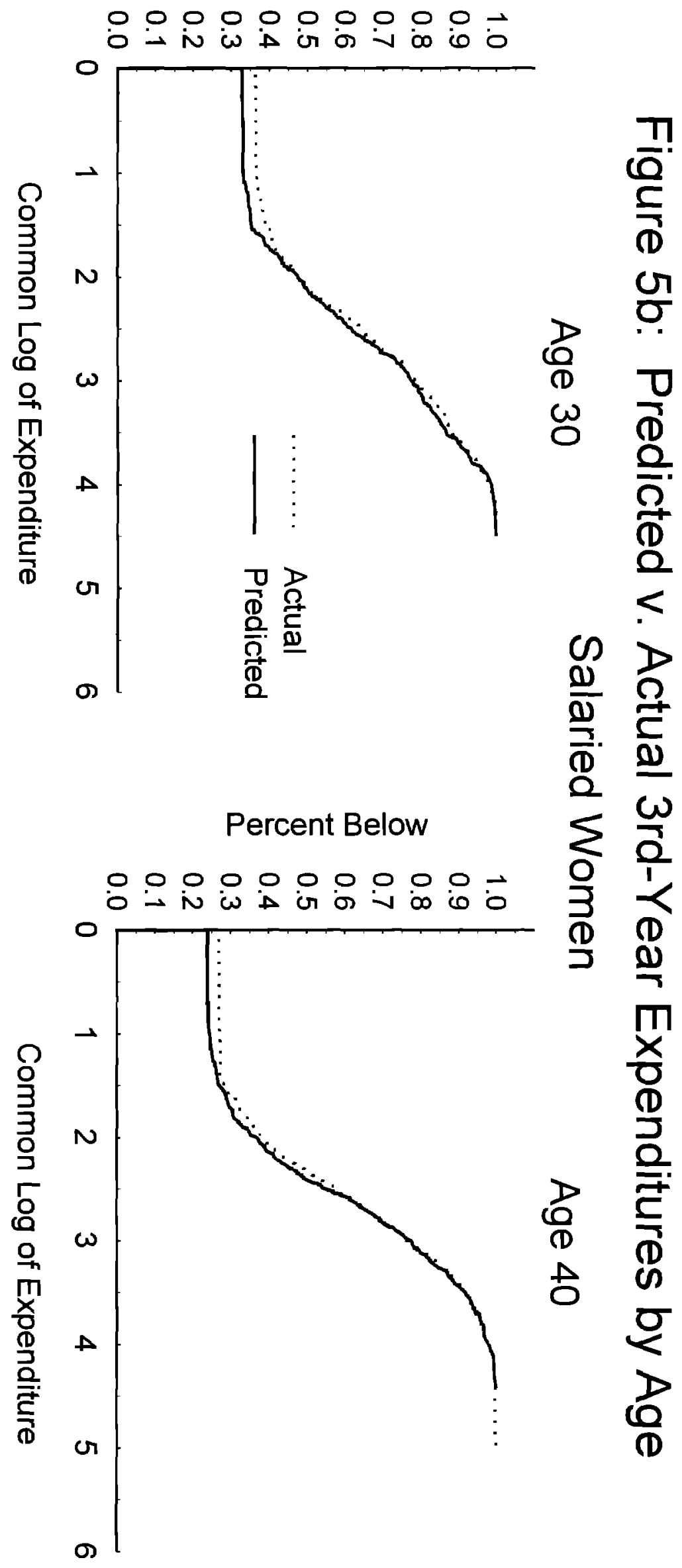
Percent Below
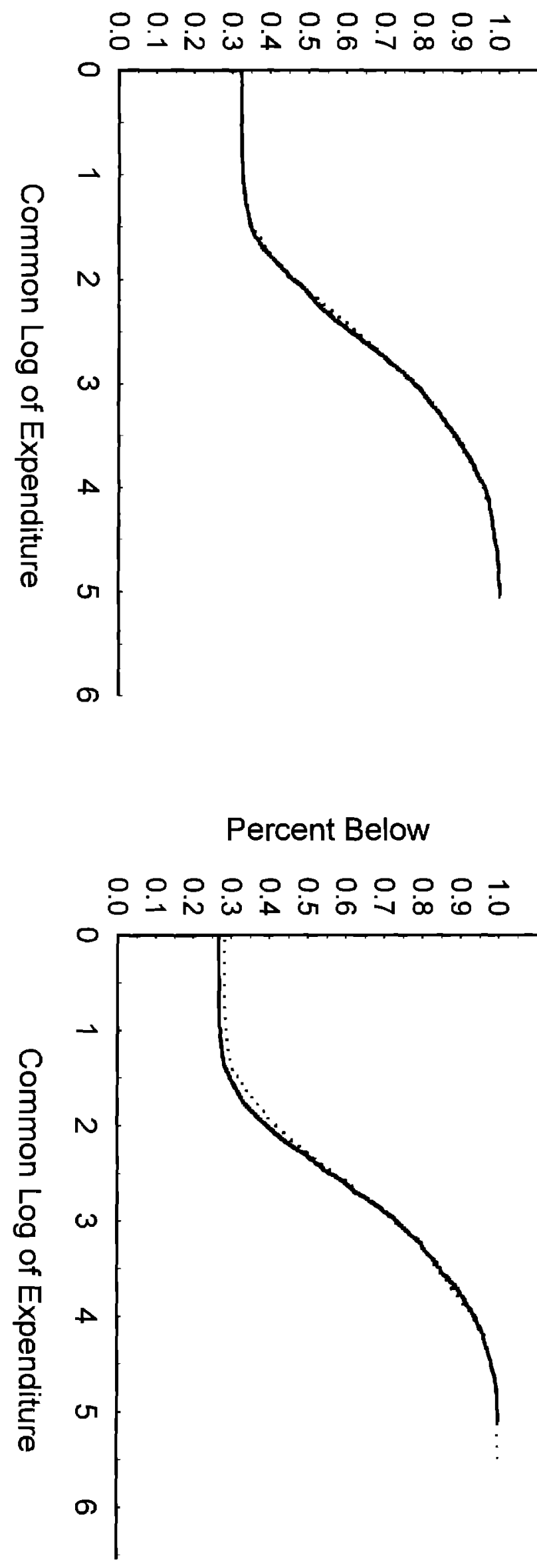

\section{Percent Below}

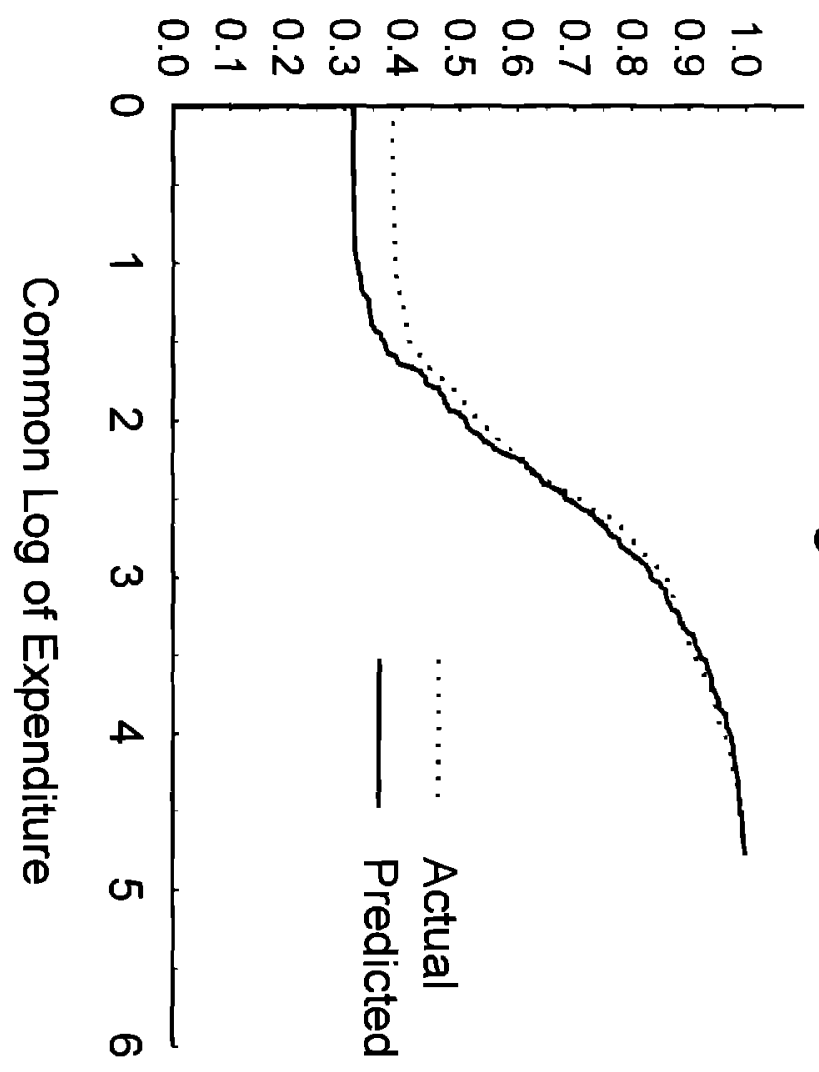

Percent Below

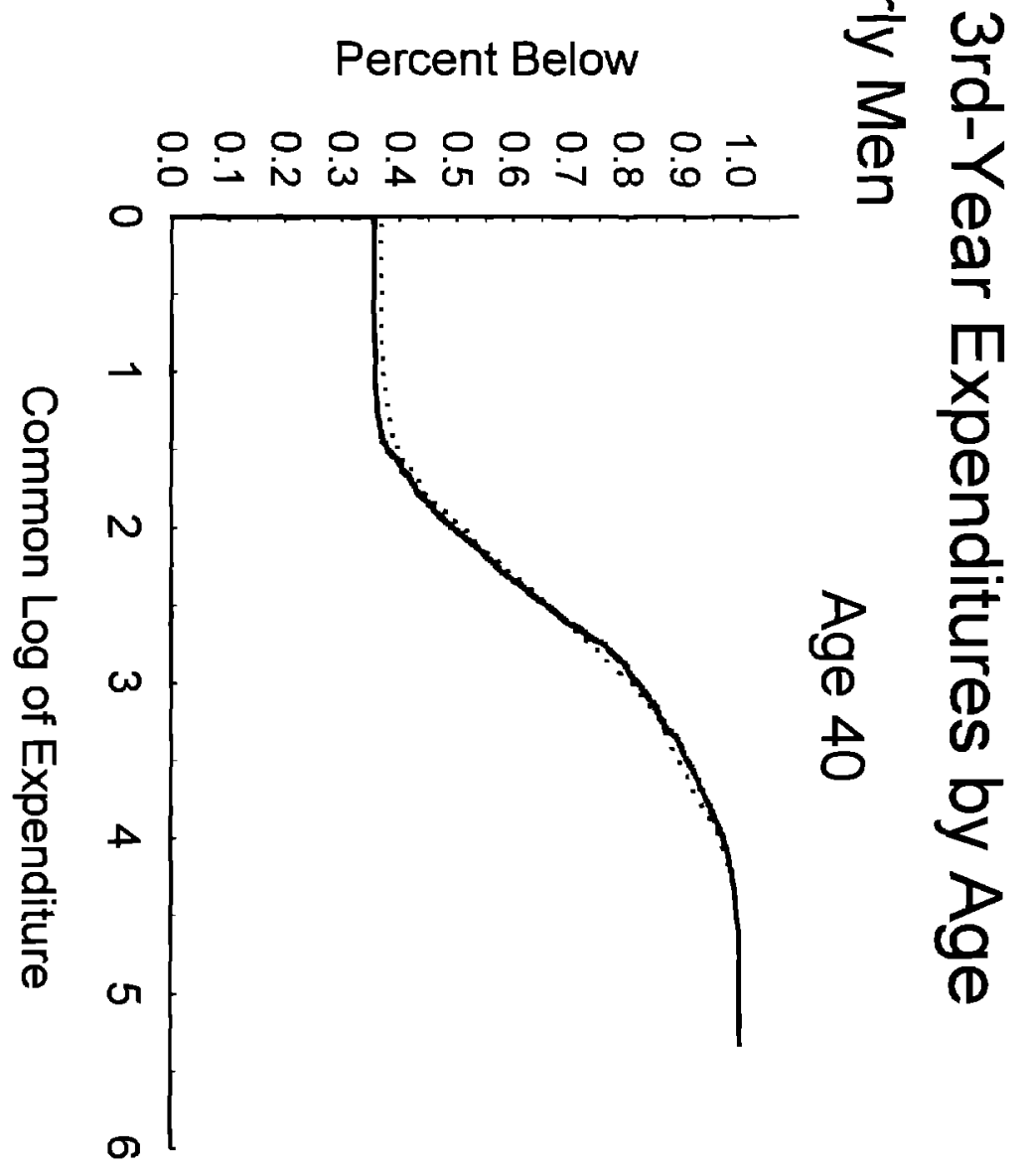

$\frac{\frac{\pi}{0}}{\frac{1}{7}}$

Dे
(1)
व

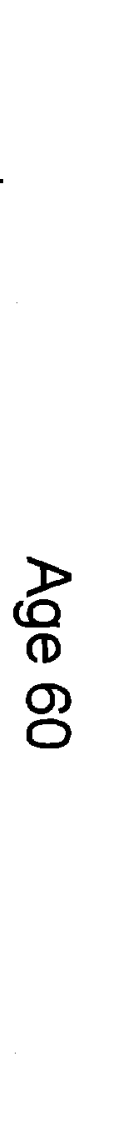


Percent Below

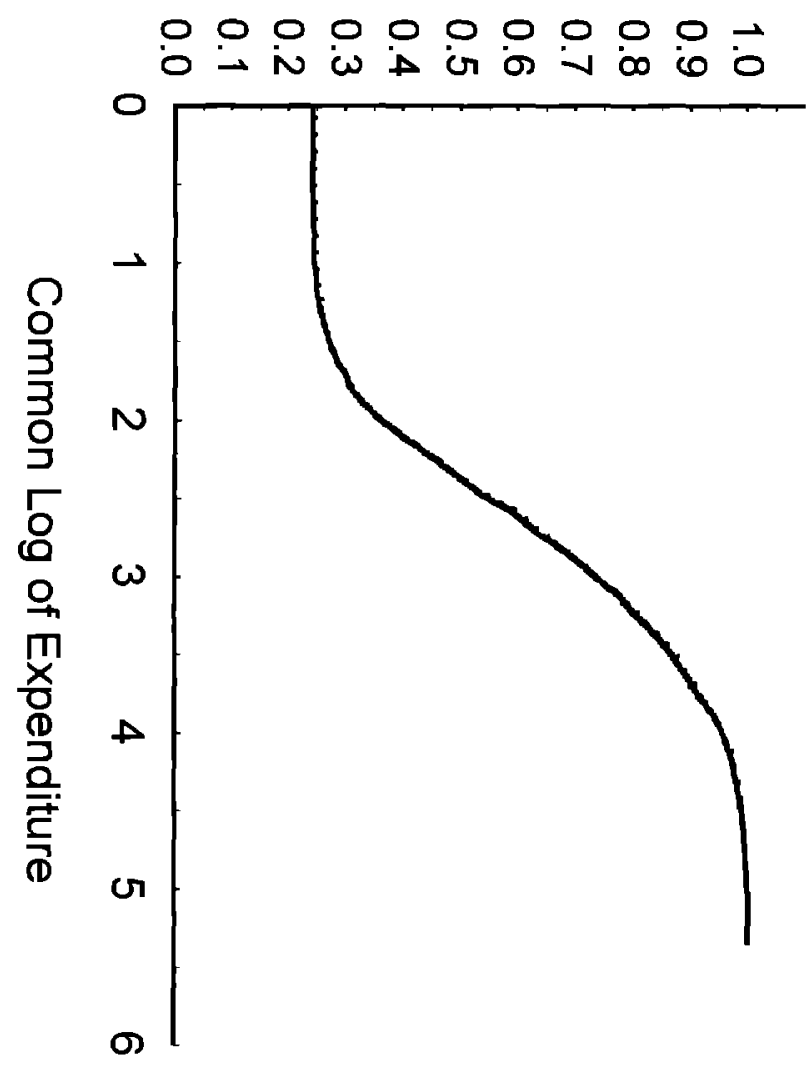

Percent Below

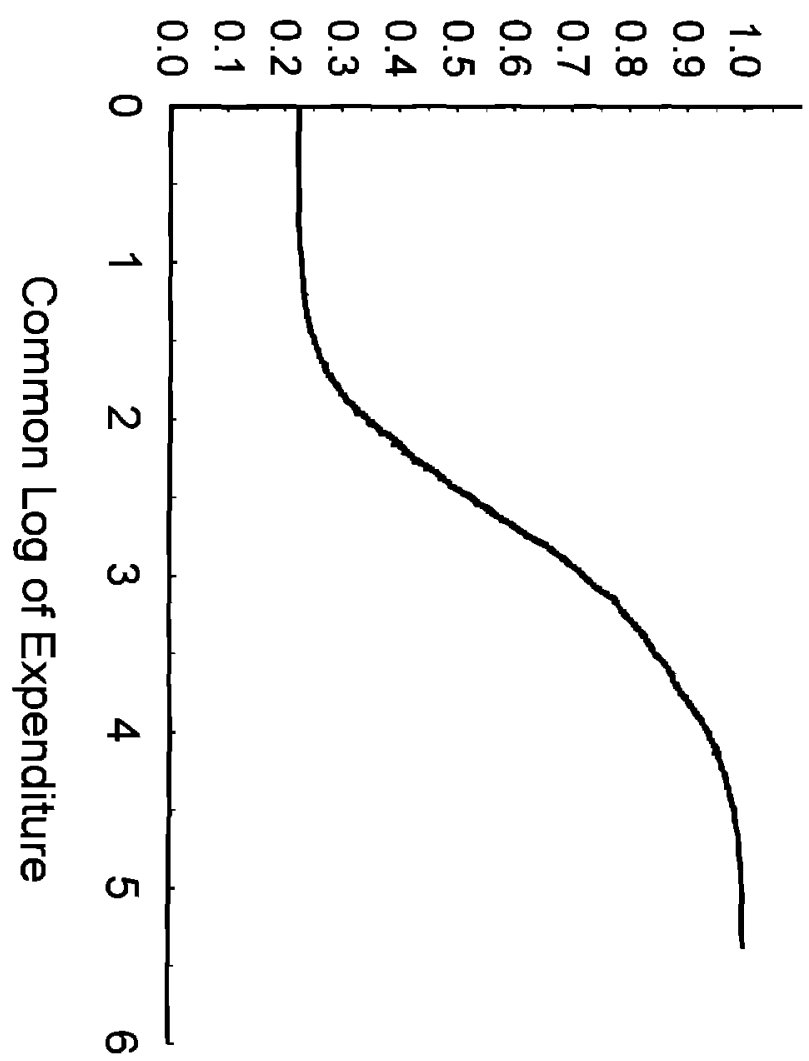

Percent Below
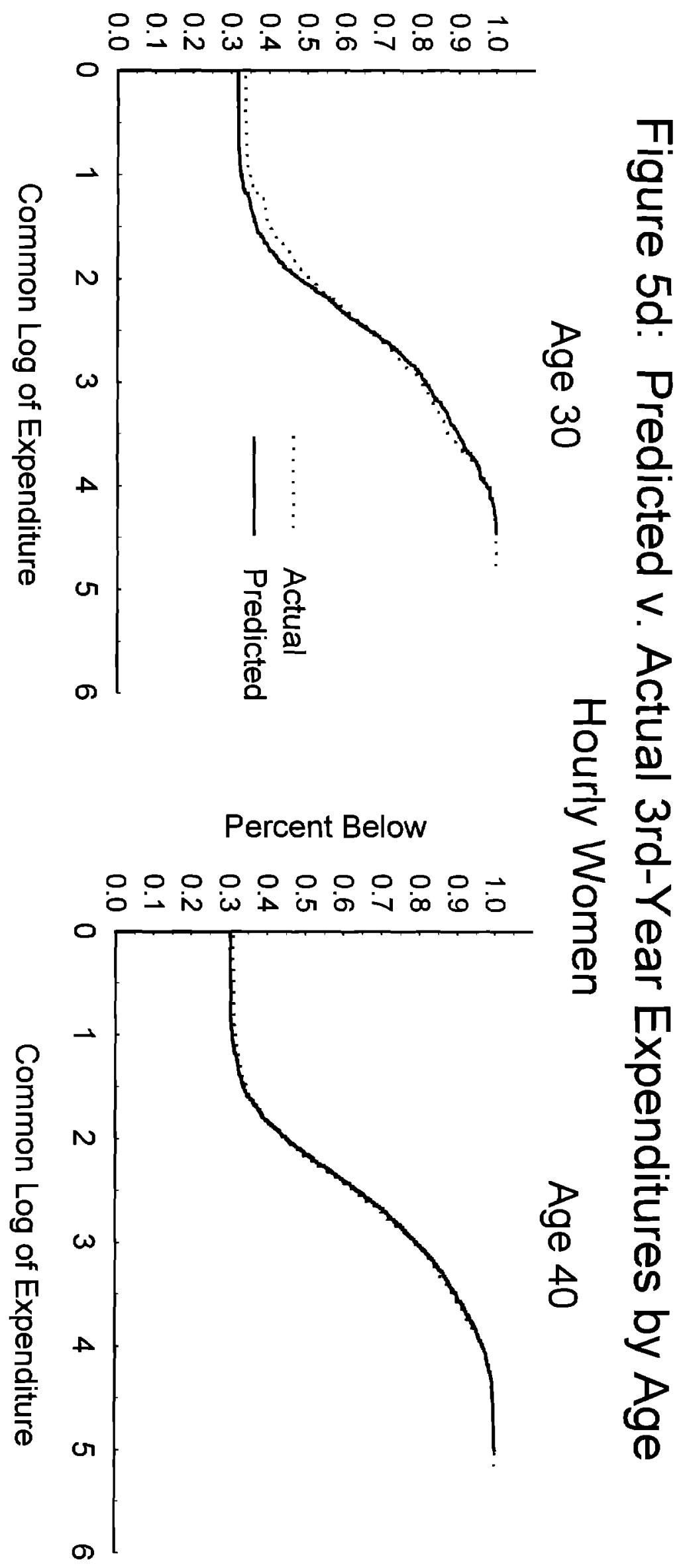
Percent Below

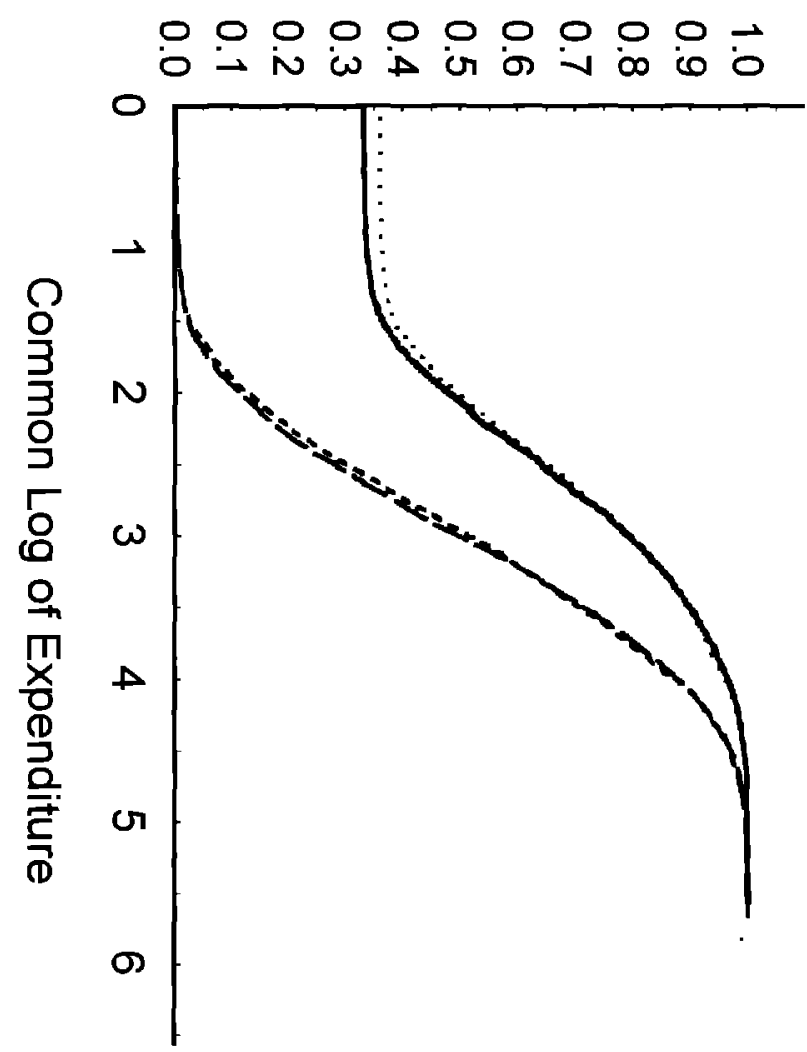

Percent Below

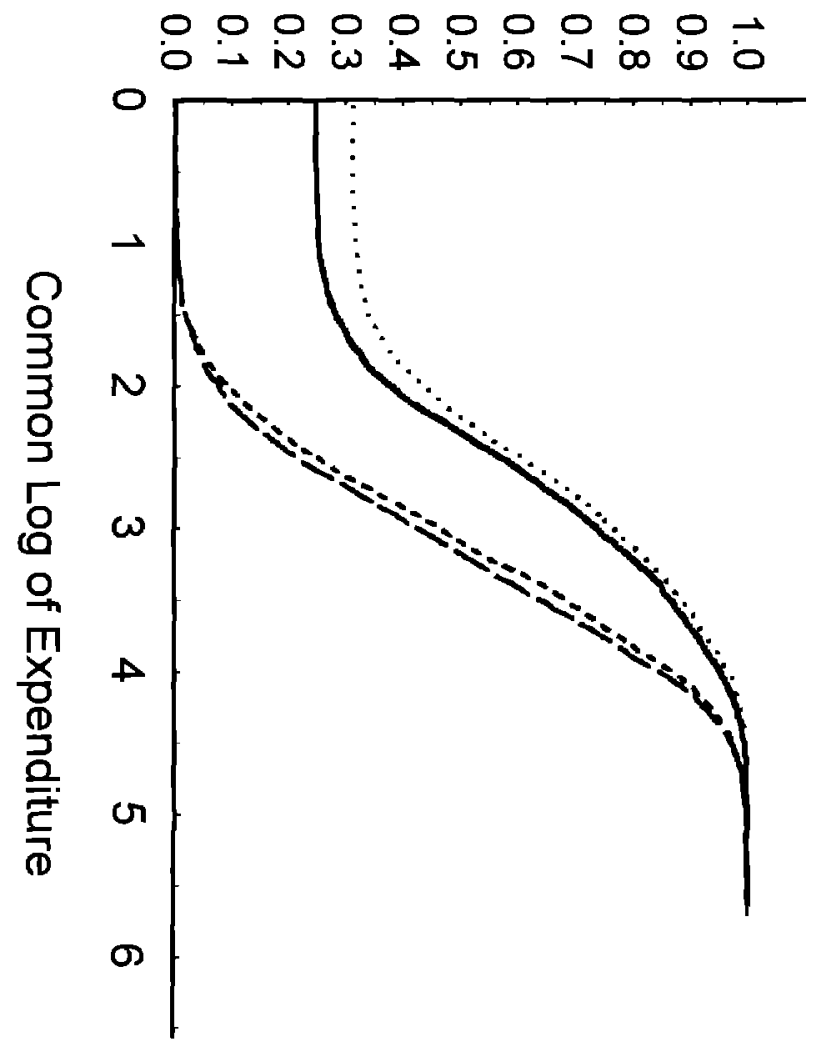

Percent Below

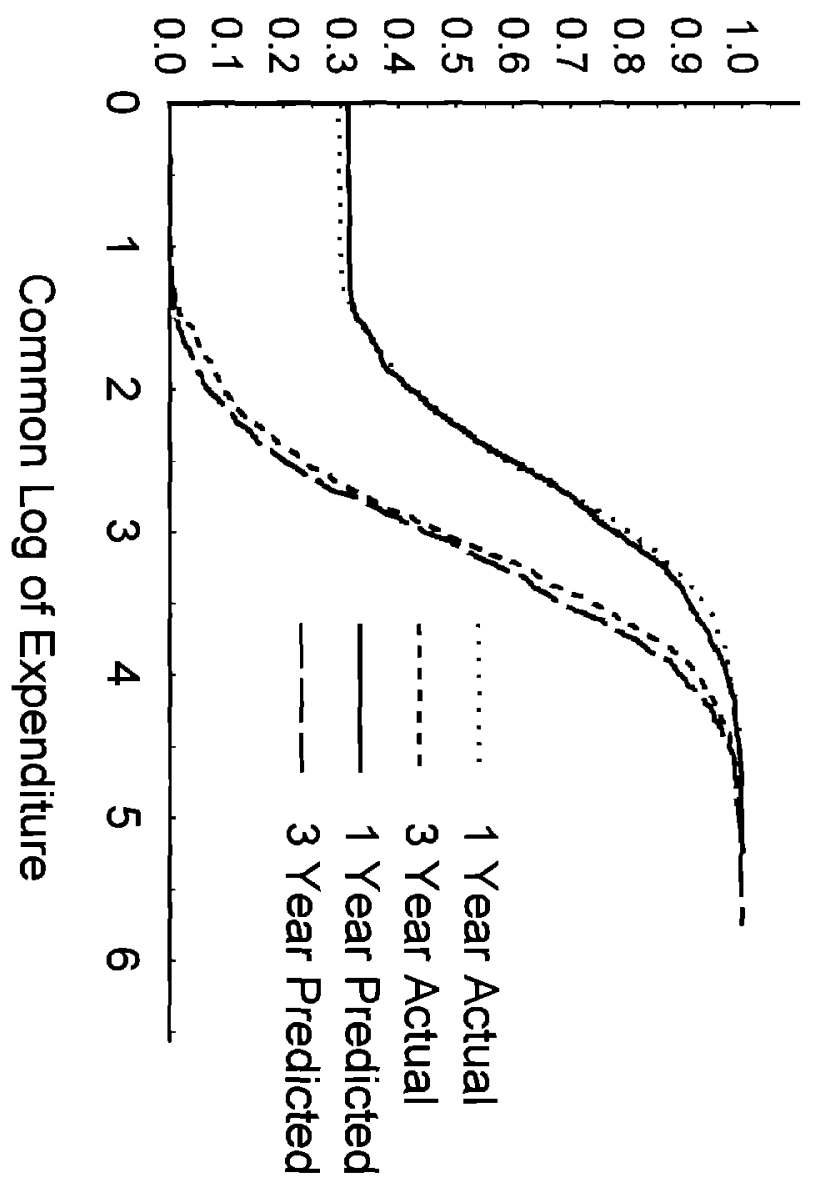

Percent Below

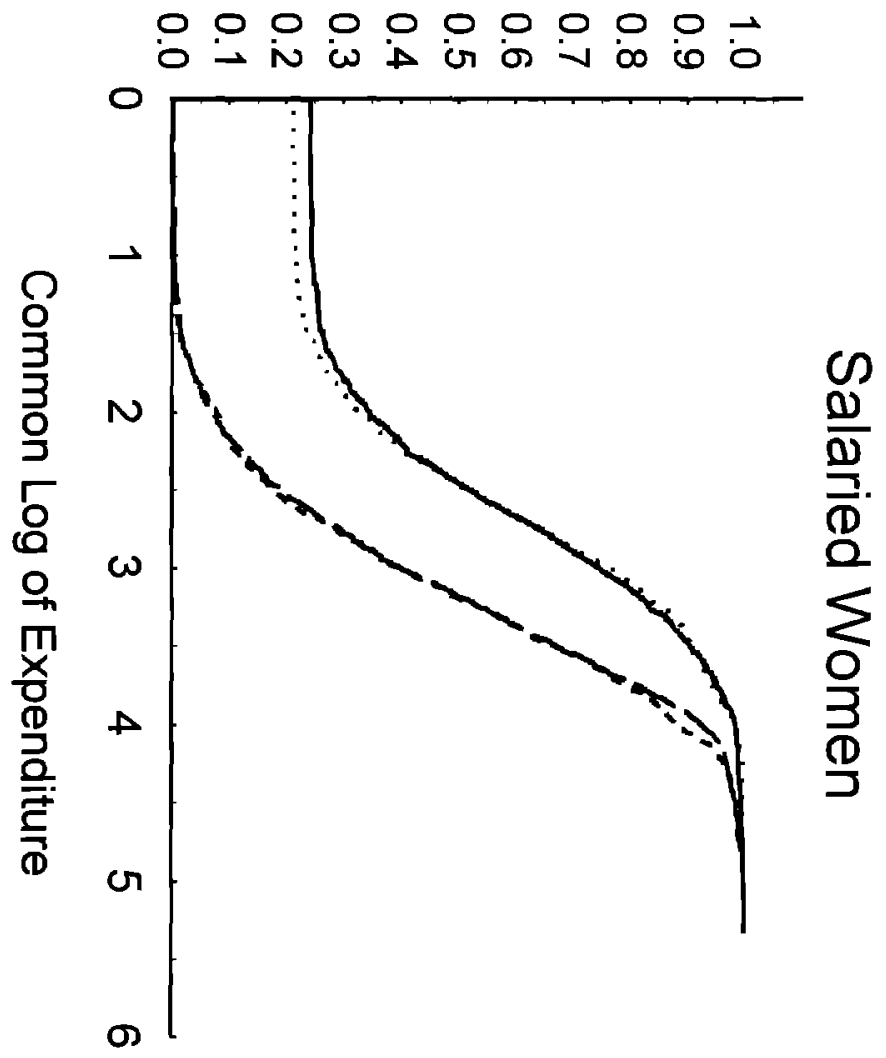

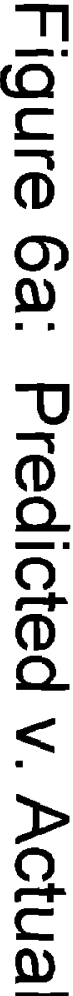
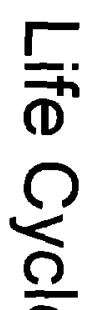

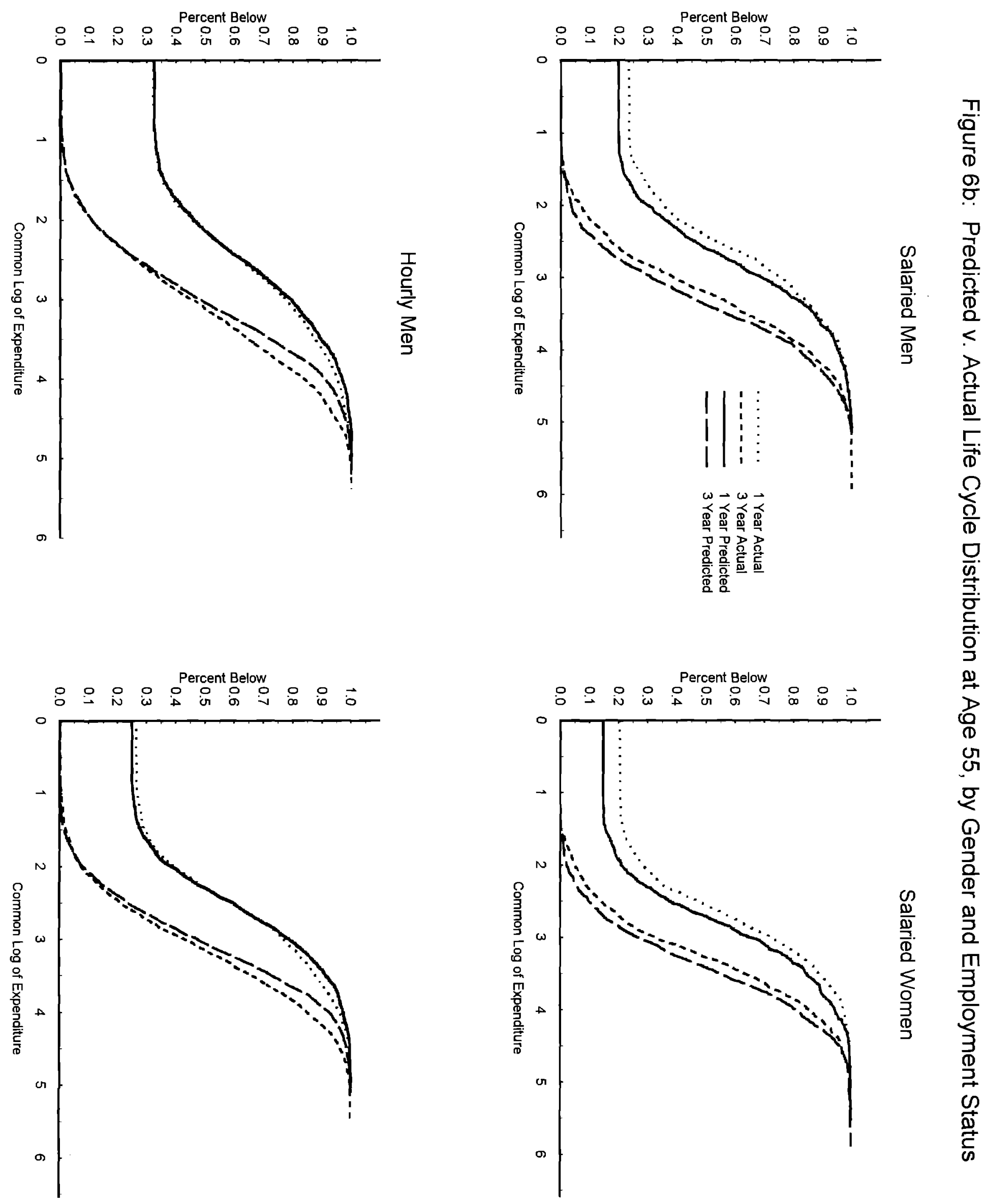

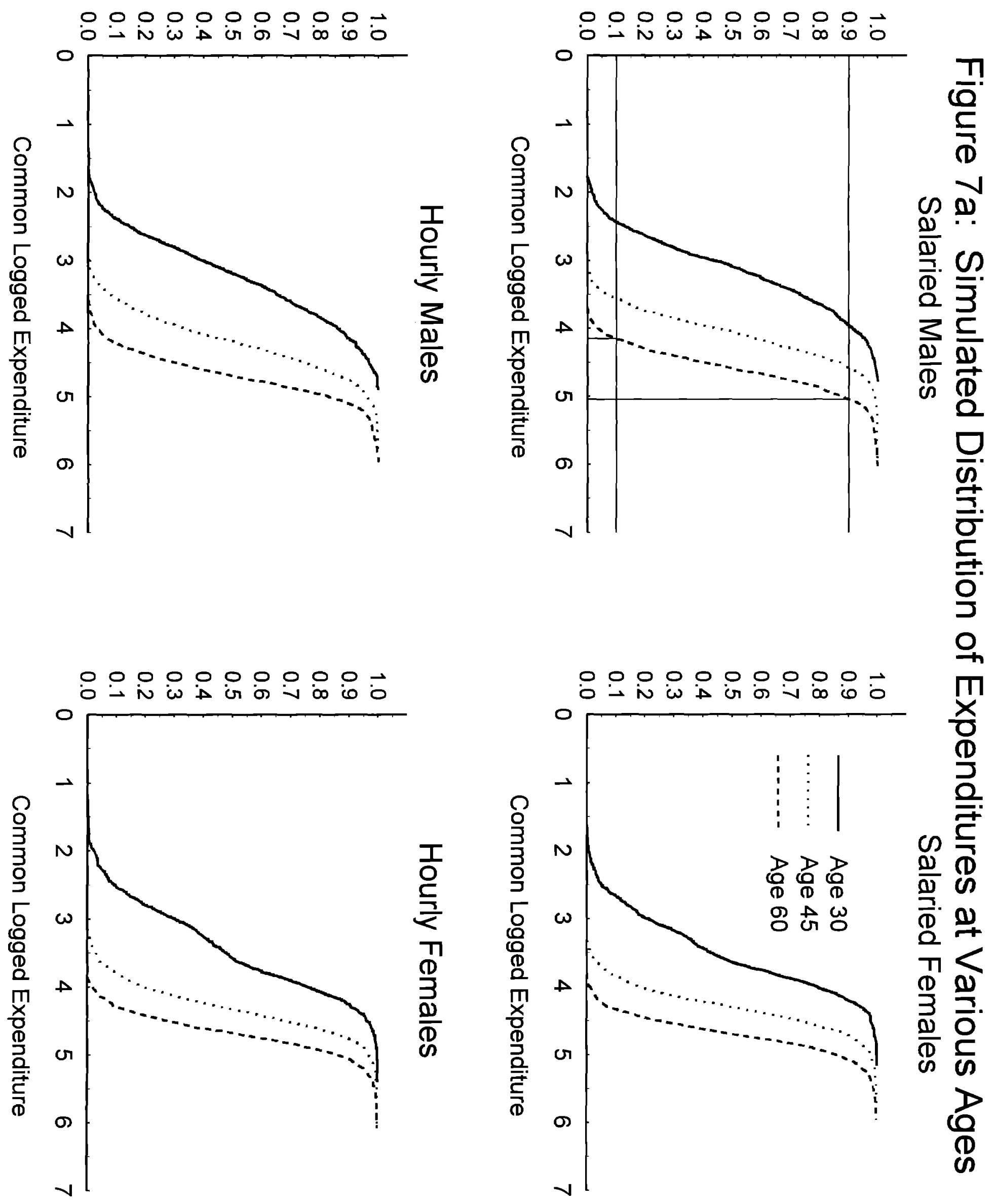
Percent of Individuals

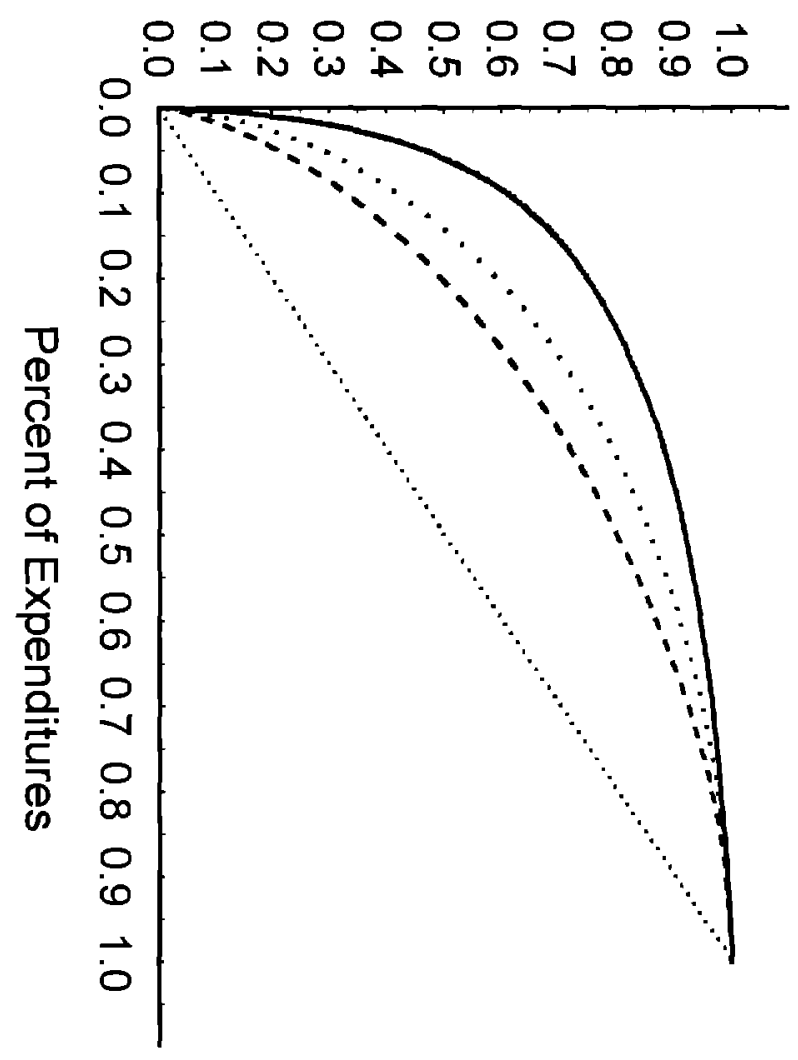

Percent of Individuals

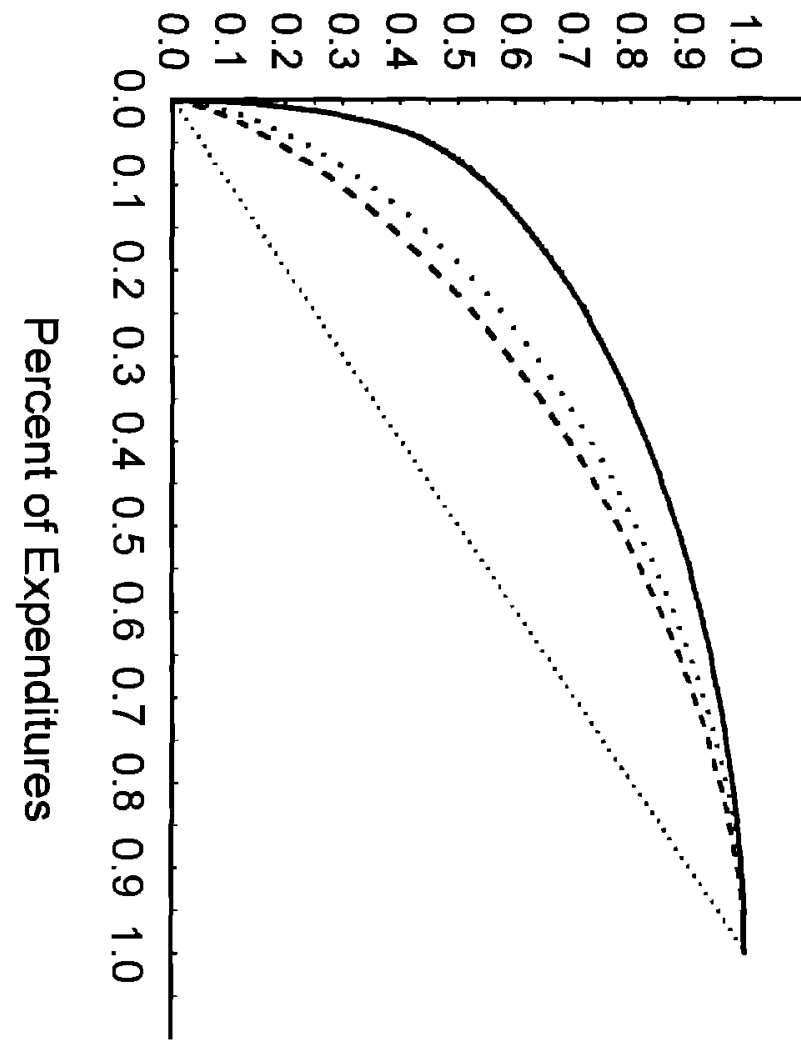

Percent of Individuals

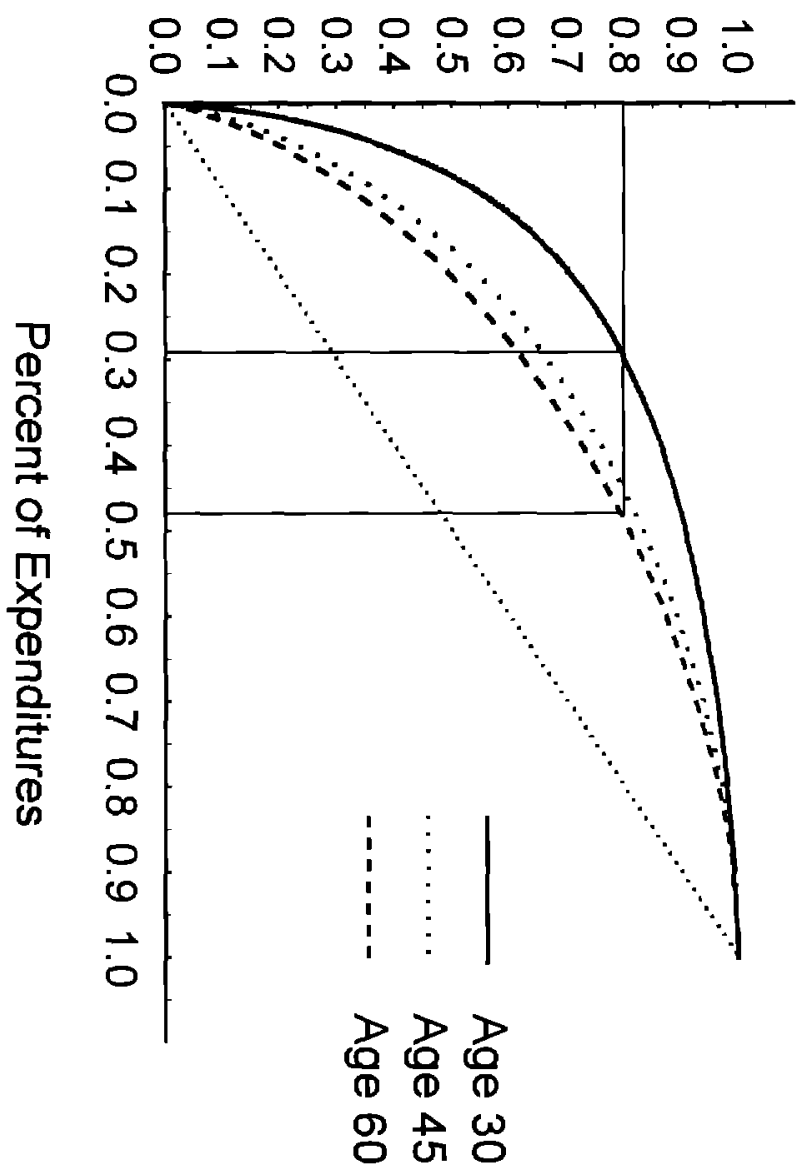

Percent of Individuals

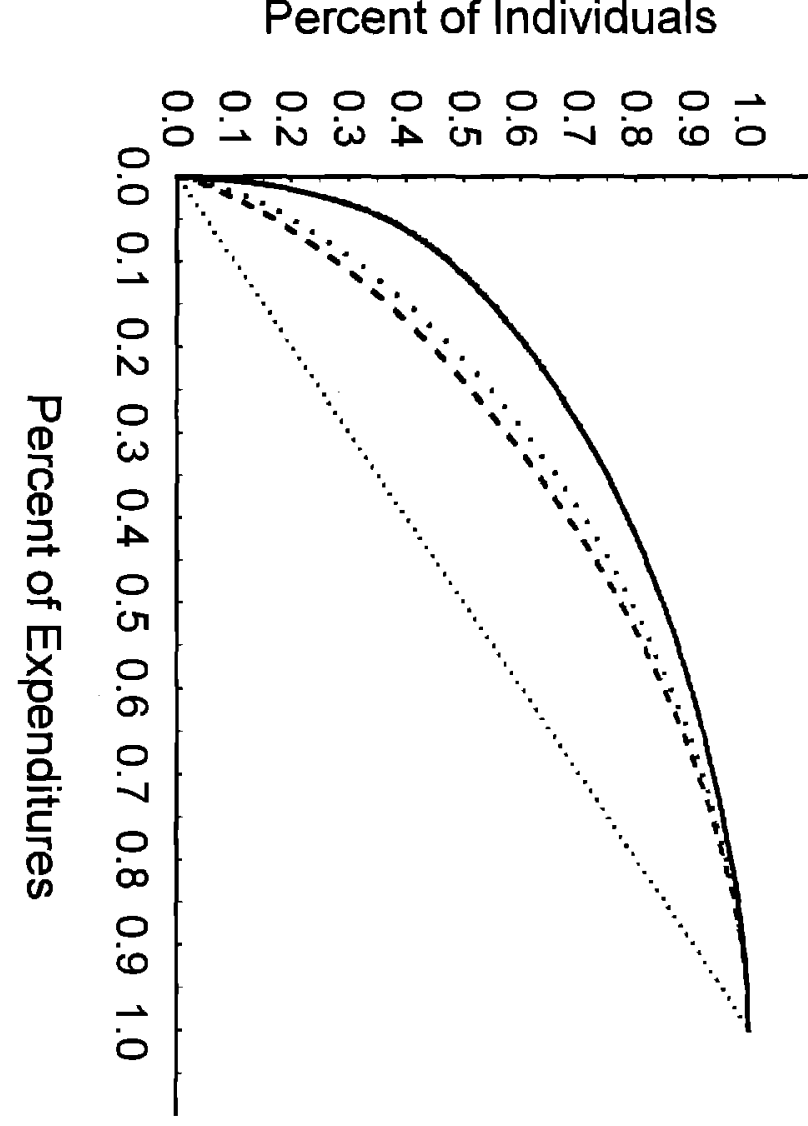

$7 \pi$

$\frac{1}{\frac{1}{O}}$

工
을
$\frac{1}{2}$
$\frac{1}{1}$
$\frac{0}{3}$
$\frac{0}{D}$

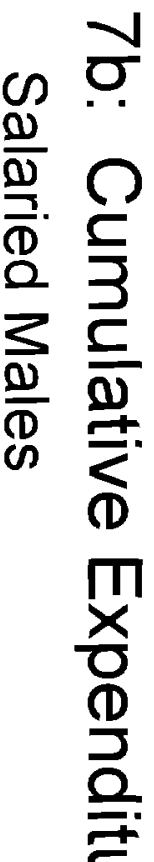

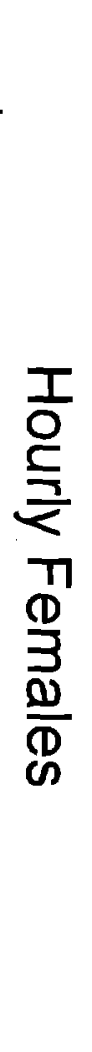


Percent Below

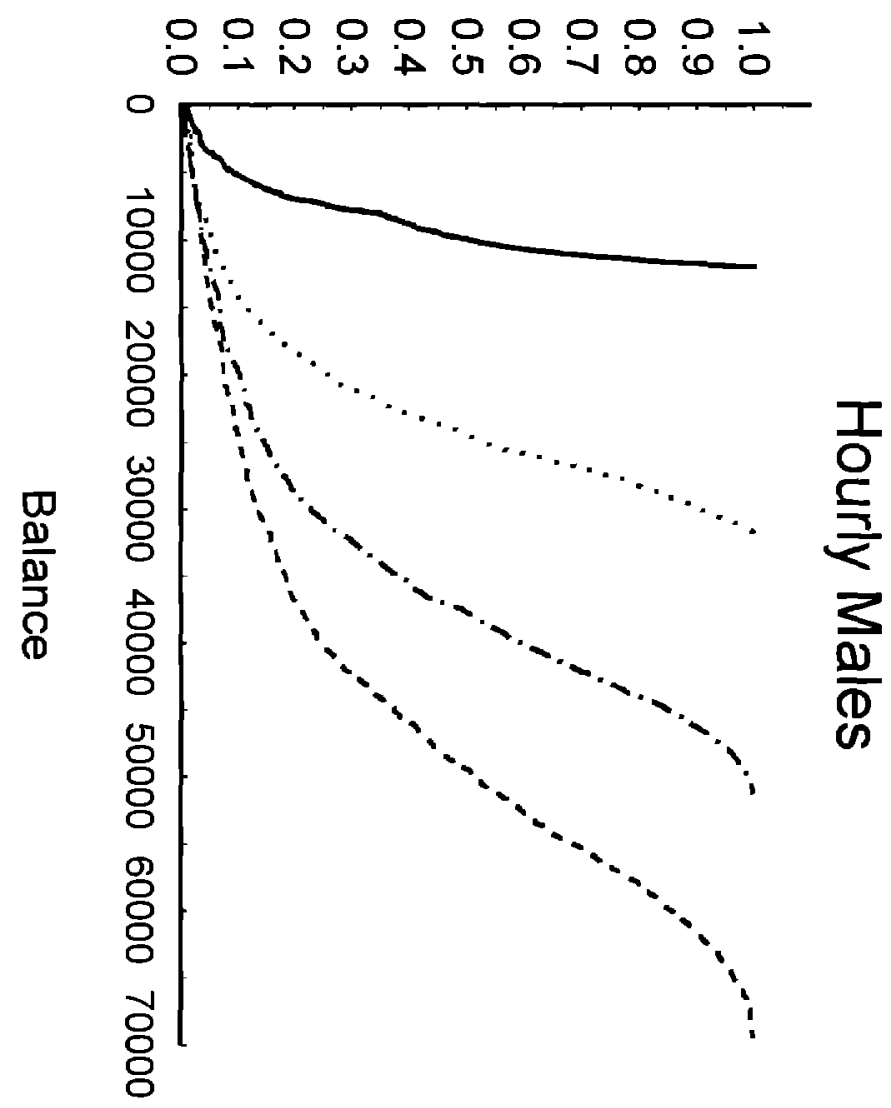

Percent Below

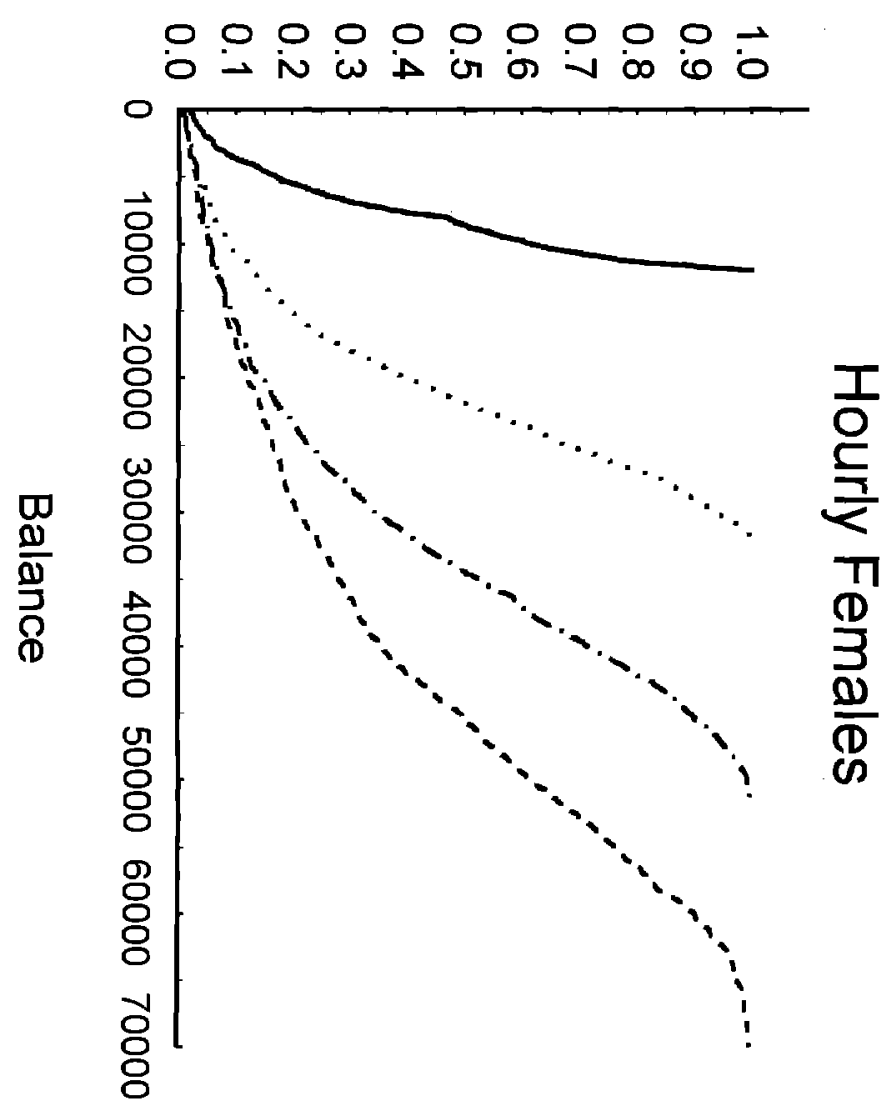

Percent Below

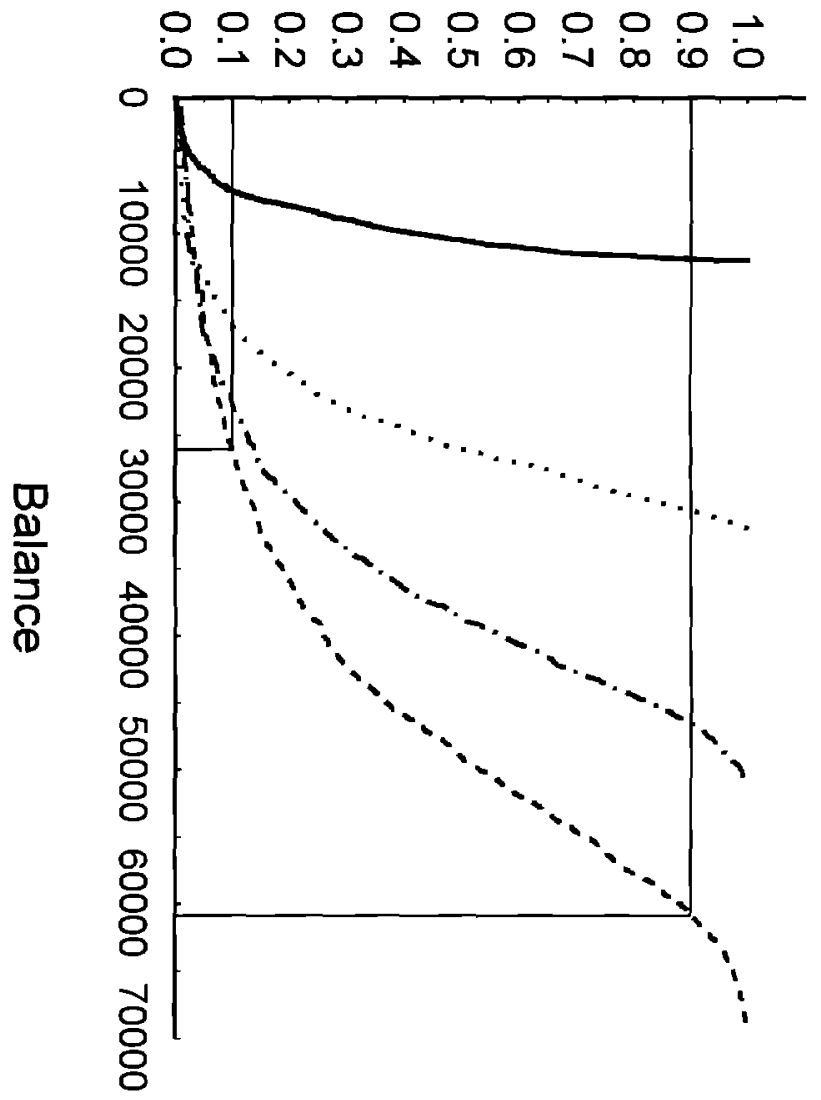

C $\frac{\pi}{\frac{0}{0}}$

$\infty$

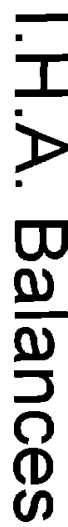

Percent Below

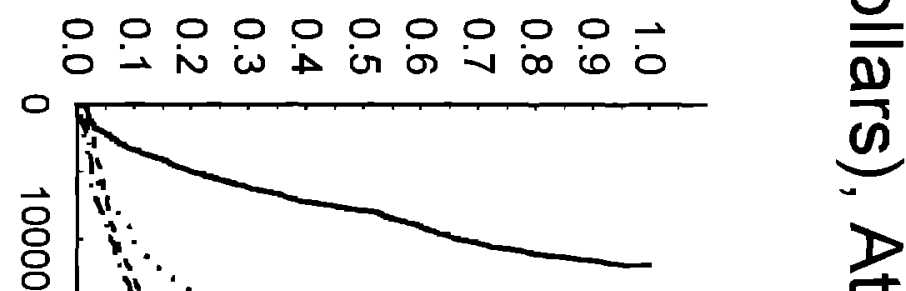

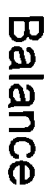

응

응

응

C

C

(D)

당

응

ठั

D
古
Q
吕
D

古古古古

잉항 
Percent Below

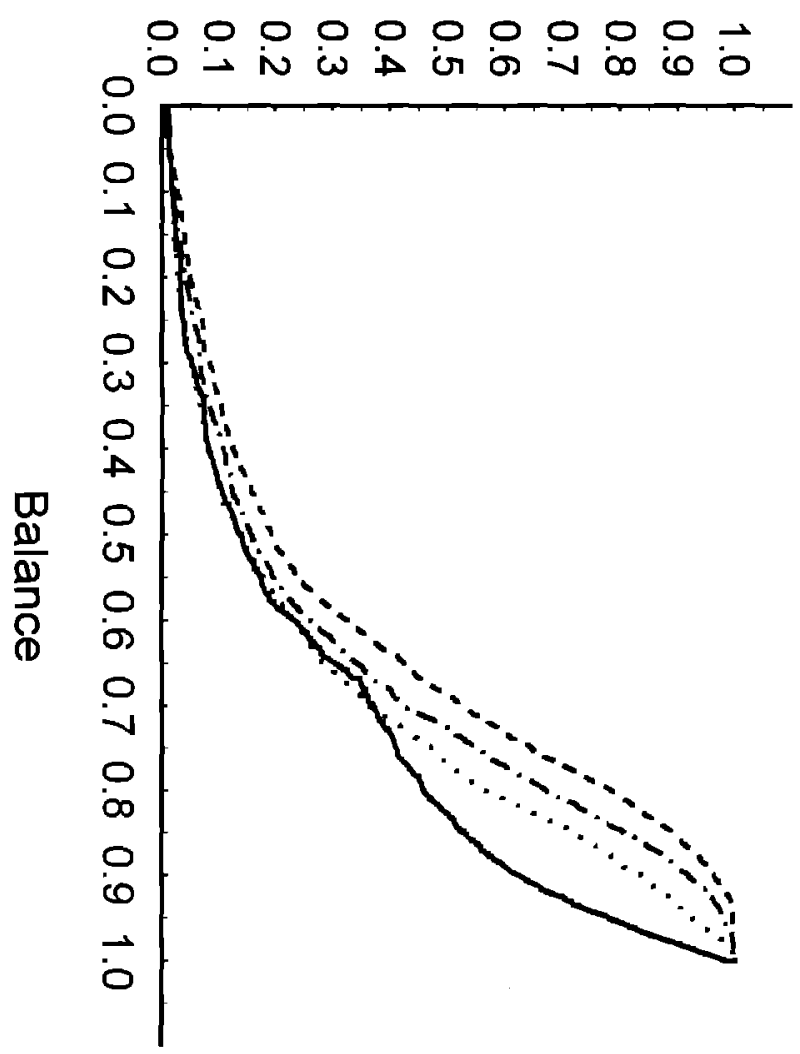

Percent Below

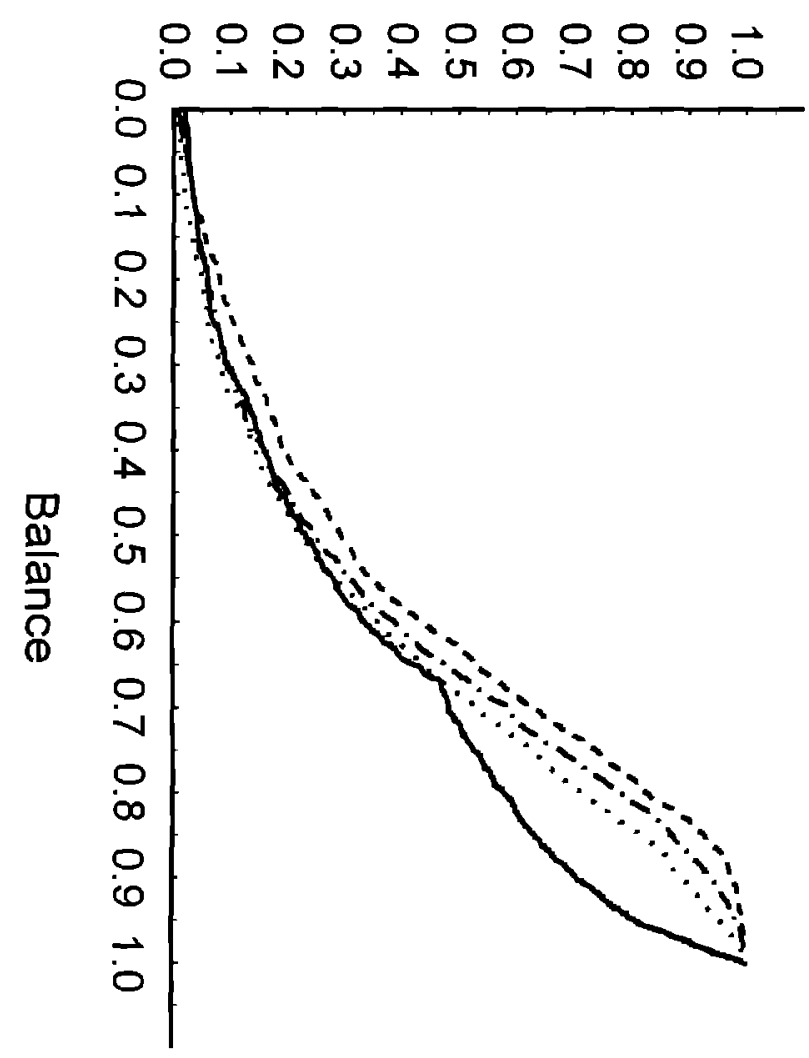

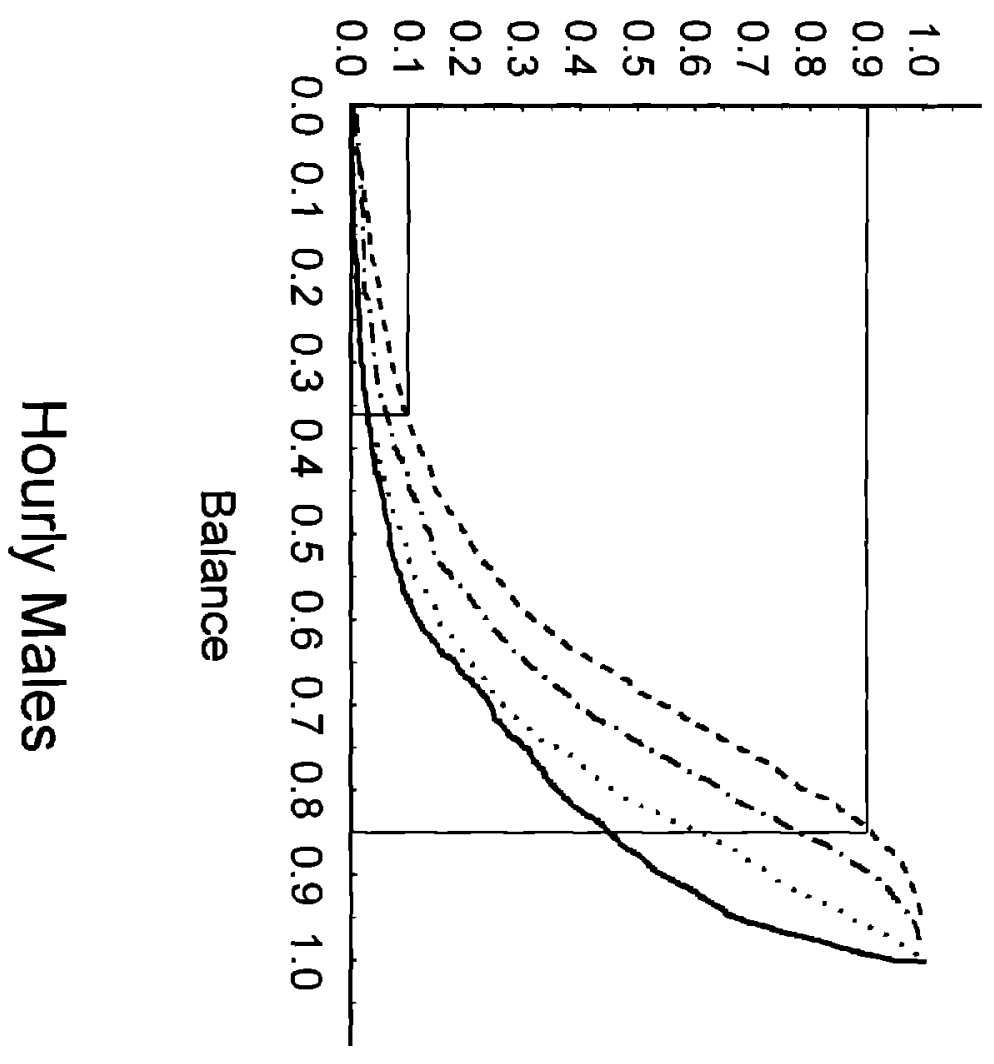

\section{Percent Below}

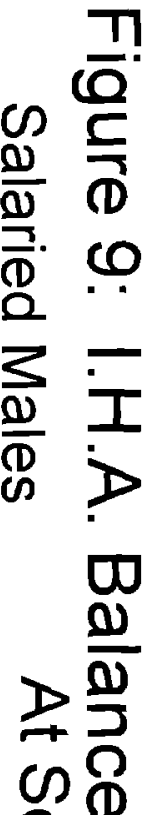

D ( )

ฉิ

Percent Below

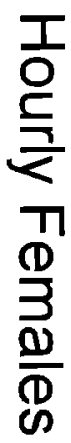

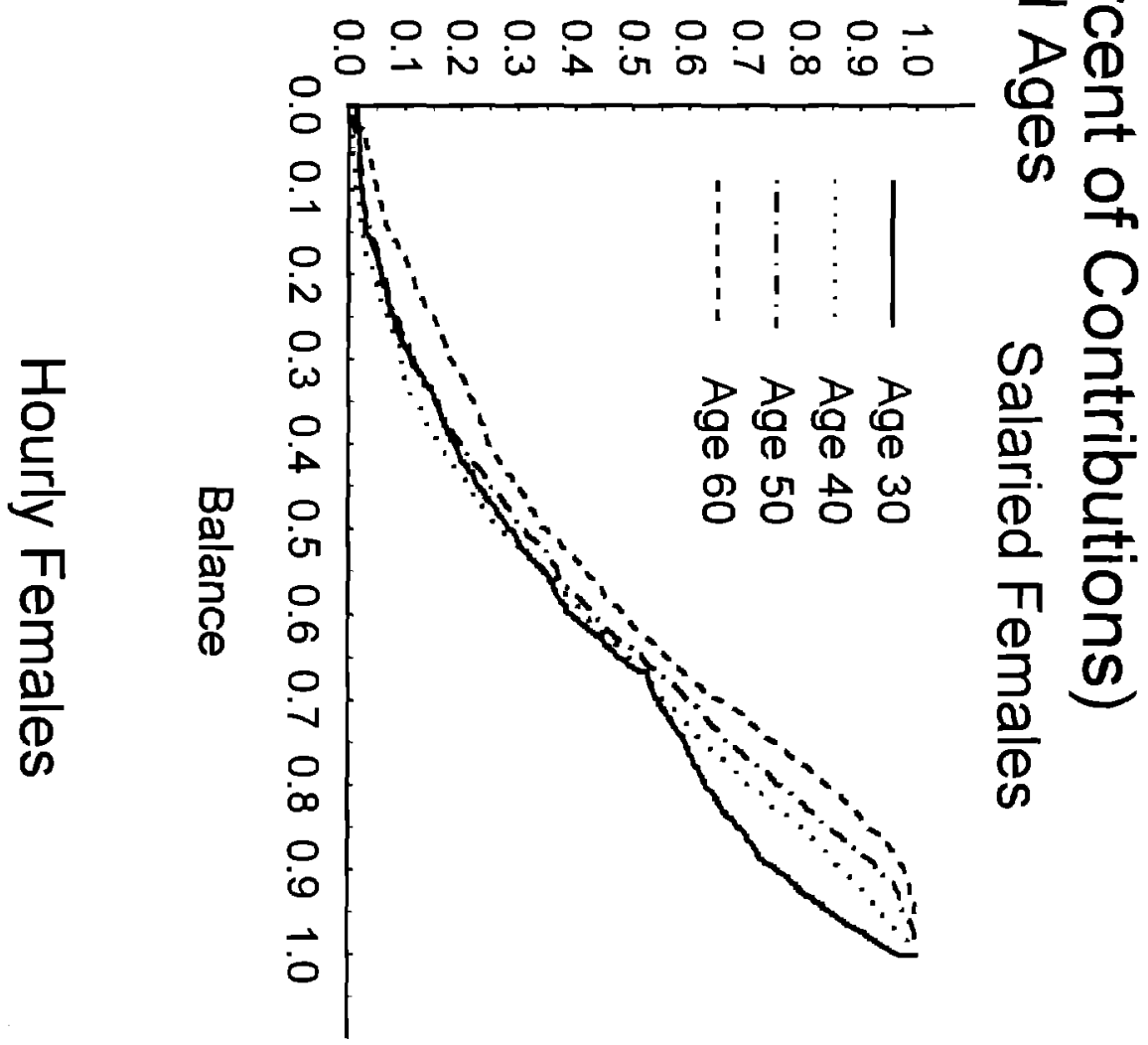


Mean Balance (Dollars)

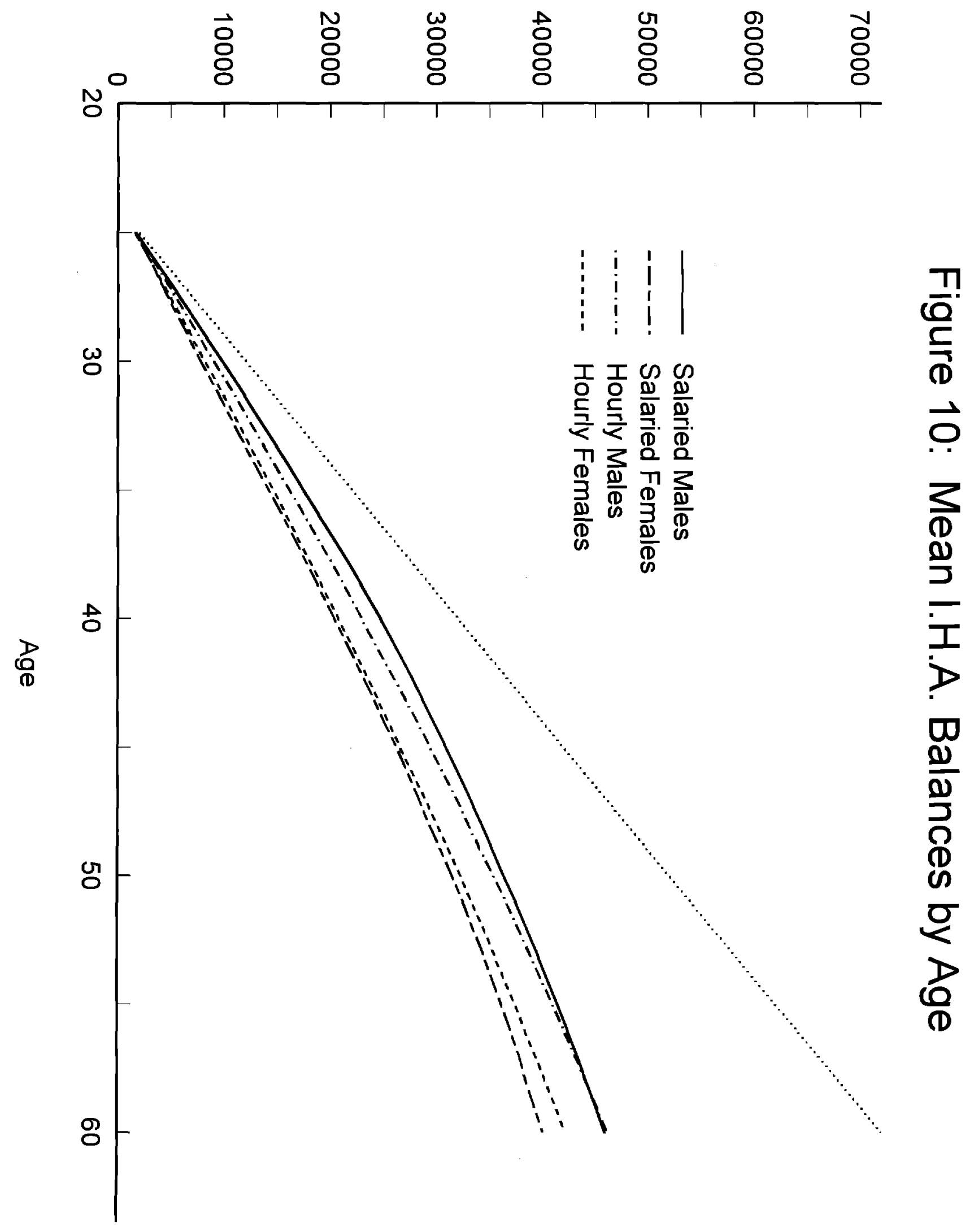




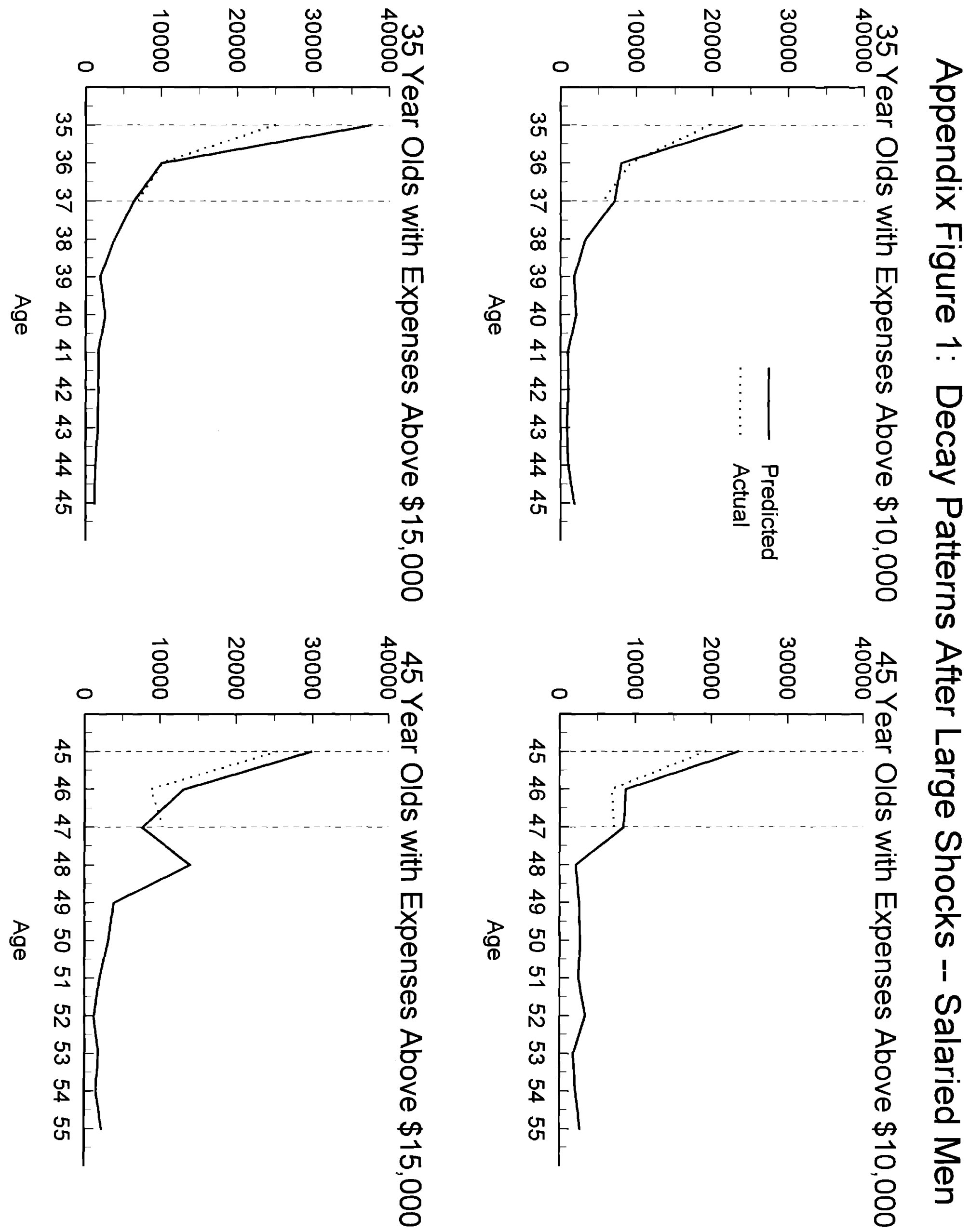

